Portland State University

PDXScholar

Spring 3-26-2013

\title{
Cultural Behavior in Post-Urbanized Brazil: The Cordial Man and Intrafamilial Conflict
}

Thais La Rosa

Portland State University

Follow this and additional works at: https://pdxscholar.library.pdx.edu/open_access_etds

Part of the Family, Life Course, and Society Commons, and the Social Psychology and Interaction Commons

Let us know how access to this document benefits you.

\section{Recommended Citation}

La Rosa, Thais, "Cultural Behavior in Post-Urbanized Brazil: The Cordial Man and Intrafamilial Conflict" (2013). Dissertations and Theses. Paper 667.

https://doi.org/10.15760/etd.667

This Thesis is brought to you for free and open access. It has been accepted for inclusion in Dissertations and Theses by an authorized administrator of PDXScholar. Please contact us if we can make this document more accessible: pdxscholar@pdx.edu. 
Cultural Behavior in Post-Urbanized Brazil:

The Cordial Man and Intrafamilial Conflict

by

Thais La Rosa

A thesis submitted in partial fulfillment of the requirements for the degree of

\author{
Master of Arts \\ in \\ Conflict Resolution
}

Thesis Committee:

Robert Gould, Chair

Rachel Cunliffe

Cynthia Sloan

Portland State University

2013 


\begin{abstract}
Cultures, subcultures, and individuals occupy different positions in the lowcontext/individualistic and the high-context/collectivistic spectrum, and they shift due to factors such as urbanization, economic development and cultural globalization. In this study, I examine Sérgio Buarque de Holanda's theory of the cordial man and how it illustrates qualities of the high-context Brazilian culture. Within the framework of grounded theory, these qualities are evaluated from the perspective of intergenerational dyads - fathers and sons — that have been exposed to an urbanized and globalized environment in order to determine whether and how a shift from high-context to lowcontext is occurring. The participants were interviewed to explore perception of self, upbringing, decision-making process within the family, father and son relationships, intrafamilial communication, ways to influence and be influenced, history of conflict, and urbanization and globalization. Their responses revealed the extent to which their values were individualistic or group-oriented and if the cordial man behavior was also present in the intimacy of their homes. In sum, I reach three conclusions: technological and cultural globalization propagates low-context values and behaviors; sons are in a transitional state, in which individual goals are relevant enough to challenge parental expectations, but still cause guilt when pursued; and, the cordial man still exists in the urban and globalized world. Implications for families, family therapists, counselors and mediators are discussed.
\end{abstract}




\section{Dedication}

I would like to dedicate this thesis to my family. Thank you for your continued support throughout my educational growth.

I thank my life partner-Pablo_-for the endless dialogues about this research topic and the valuable input you have given me. Your quest for the truth inspires me. Thank you for your love and care while I was working on completing this study.

I thank Chris Dahlgren for the steady support throughout this process. Thank you for being a friend on whom I could rely while pursuing this degree. Your advice has been beneficial and appreciated.

I also would like to thank Cynthia Kenyon for sharing her home with me. Thank you for allowing me to be a part of your life. I will always cherish our talks while sitting by the fire.

Finally, I would like to thank my parents_-Evanilz and João — for giving me a solid foundation on which to stand. I thank you for your unconditional love and for believing that nothing is impossible to me. 


\section{Acknowledgements}

First, I would like to acknowledge my thesis advisor, Dr. Rachel Cunliffe. Thank you for sharing your expertise with me, and for your timely input and helpful suggestions for this study. I also thank the committee members-Dr. Rob Gould and Dr. Cynthia Sloan—whose input and suggestions helped to mold this work.

Second, I would like to thank the graduate department at Portland State University for their support in the final stages of completing this thesis. I specifically thank Margaret Everett, Courtney Hanson and Brenda Fugate.

Third, I would like to thank the P.E.O. Sisterhood, especially Diane Glase, President of Chapter IL in Longview, Washington, and Brenda Atchinson, Chairperson of the International Peace Scholarship. 


\section{Contents}

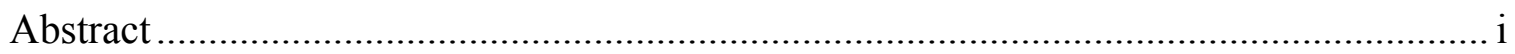

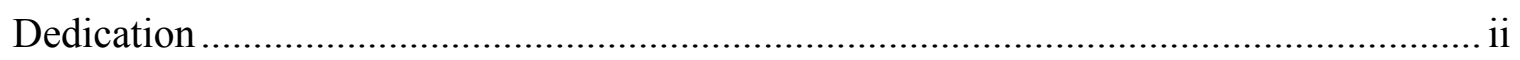

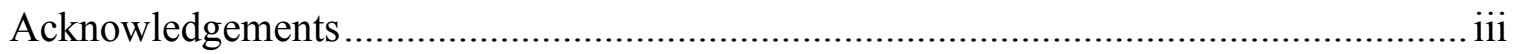

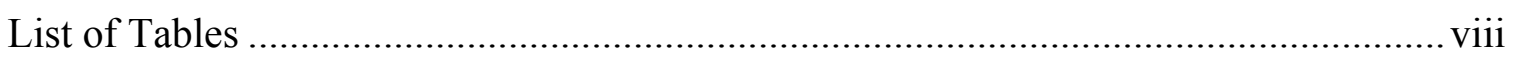

Chapter 1: Cultural Behavior in Post-Urbanized Brazil: The Cordial Man and

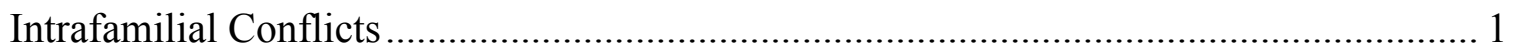

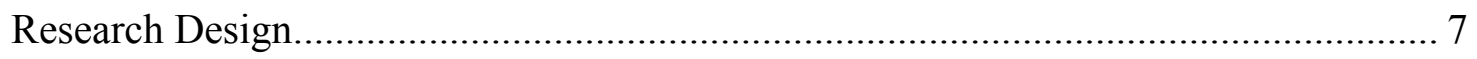

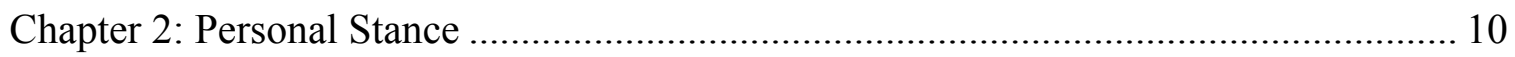

Chapter 3: Review of the Literature I: Intercultural communication ........................... 16

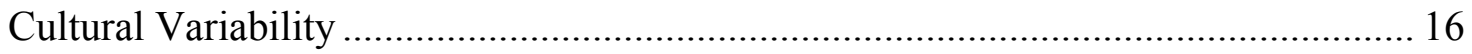

Low-Context and High-Context Systems. ................................................... 18

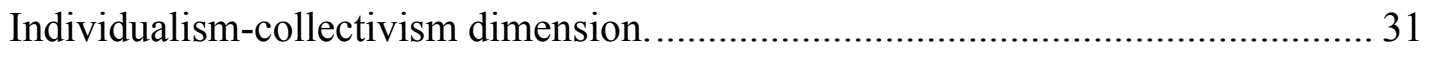

Choosing Hall's low-context/high-context approach. ...................................... 36

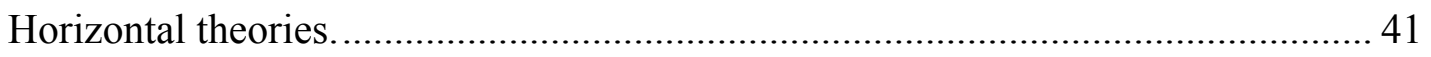

Chapter 4: Review of the Literature II: Intercultural communication in Brazil .............. 45

The Cordial Man: the Face of a High-Context System .......................................... 45

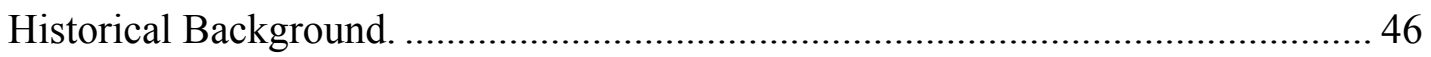

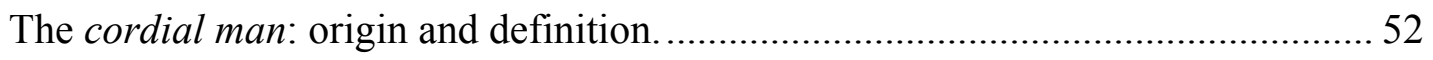

Devices used to navigate through society and mediate conflict. ........................... 60

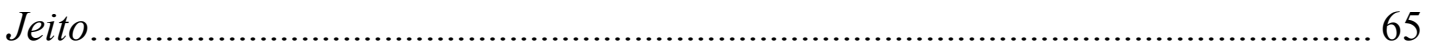

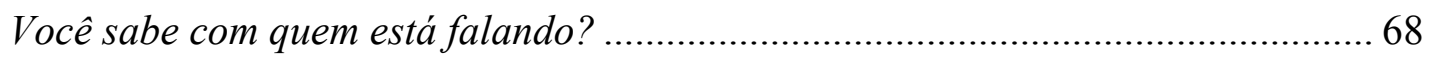

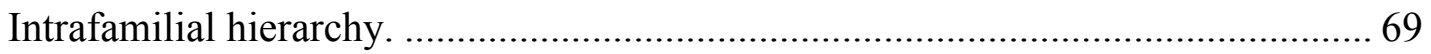


URBANIZED BRAZIL AND INTRAFAMILIAL CONFLICT V v

Urbanization and U.S.-Influenced Cultural Globalization ..................................... 71

Urbanization in Brazil after 1970 and the future of the cordial man...................... 71

U.S.-influenced cultural globalization in Brazil after 1990 and the future of the

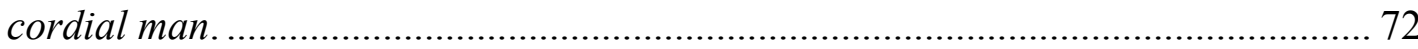

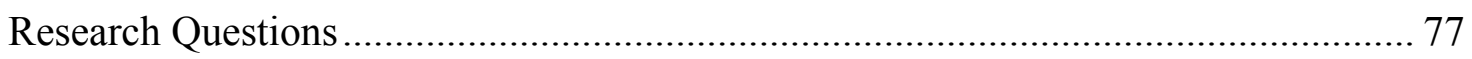

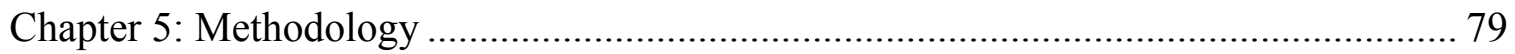

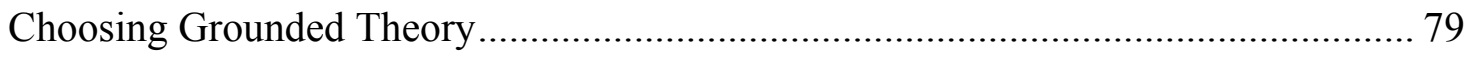

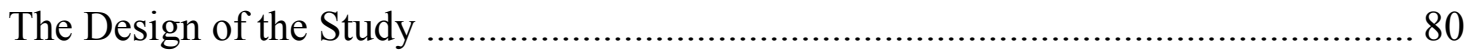

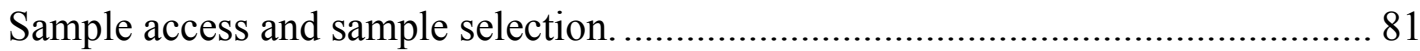

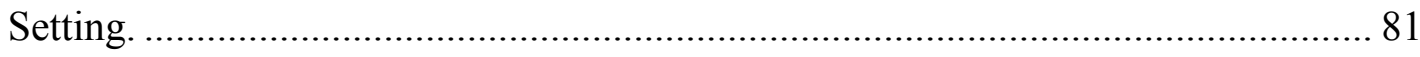

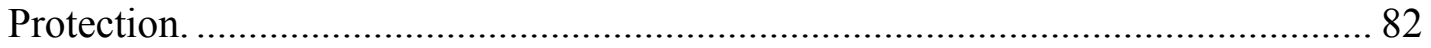

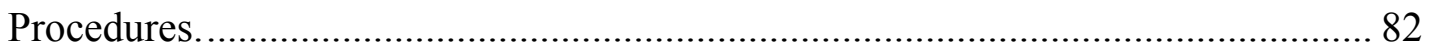

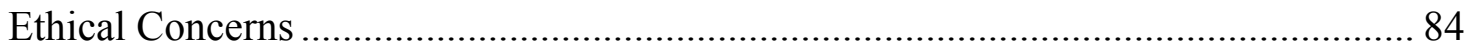

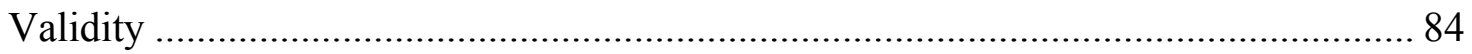

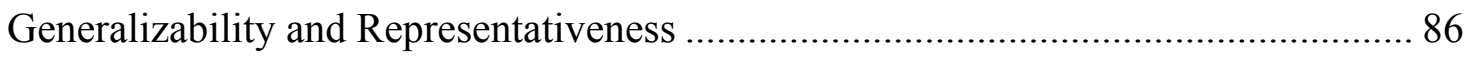

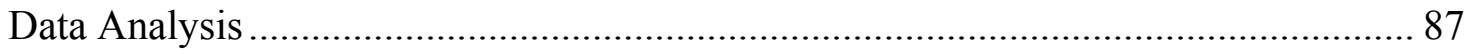

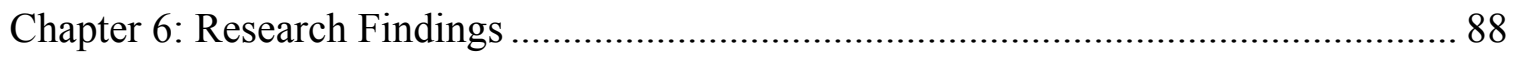

Is Brazil's younger generation-born after massive urbanization in the early 1970s and influenced by the U.S. cultural globalization in the 1990s - experiencing a shift within

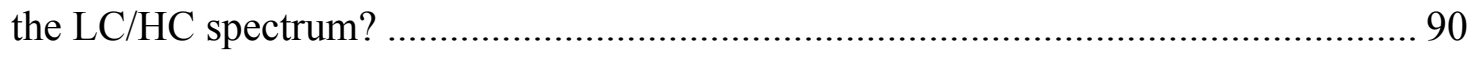

Theme I: The effects of technological and cultural globalization .......................... 91

A. The influence of television and the Internet.............................................. 91 
URBANIZED BRAZIL AND INTRAFAMILIAL CONFLICT vi

B. Wider access to information and world connectivity................................... 93

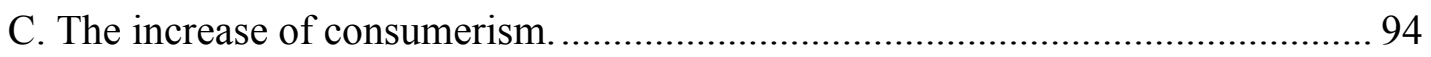

Does this shift affect intrafamilial relationships between generations that identify with

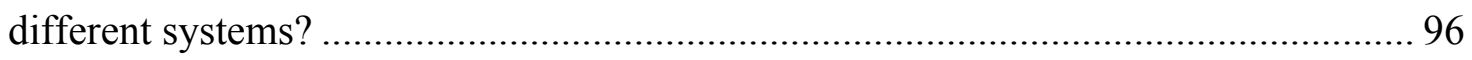

Theme II: The effects of technological and cultural globalization on the family unit . 97

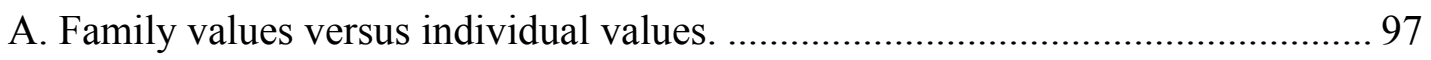

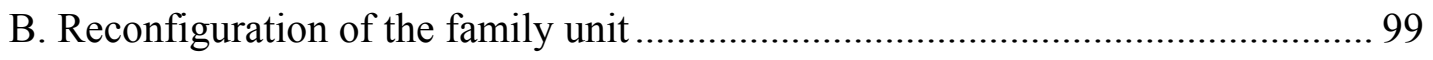

C. The lack of mindful contact among family members living in the same

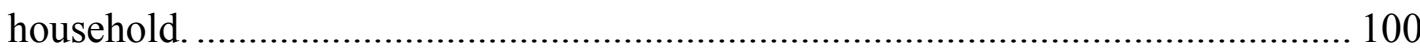

Who is the cordial man now and can he adapt to a world that is dissimilar to his rural

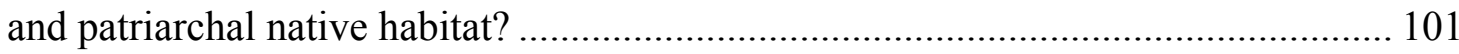

Theme III: The persistence of the cordial man .................................................... 103

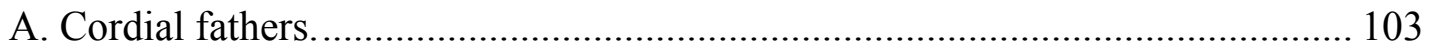

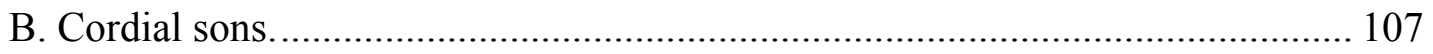

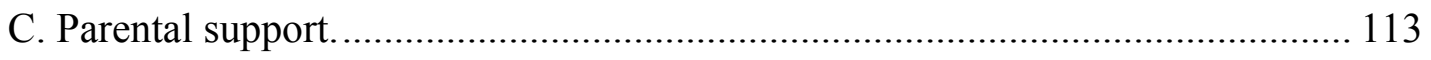

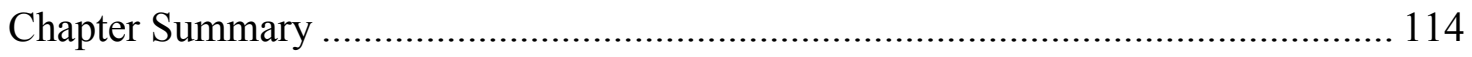

Chapter 7: Discussion and Conclusion, Limitations, Recommendation....................... 117

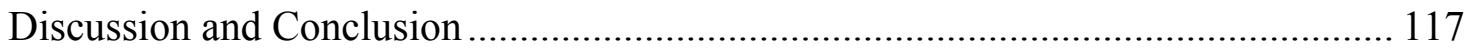

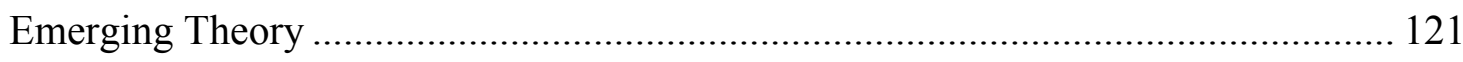

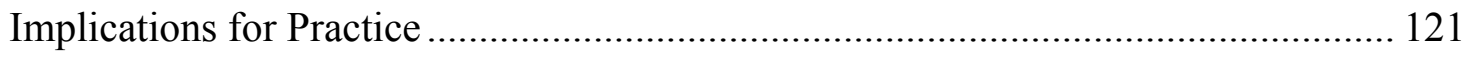

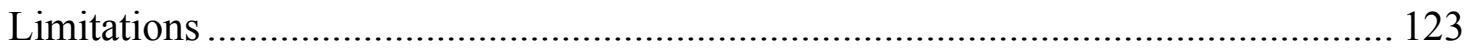

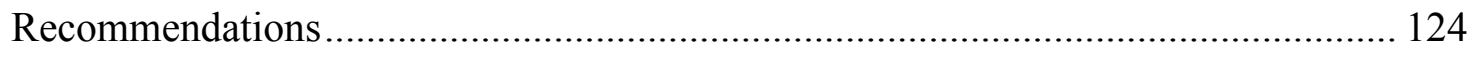




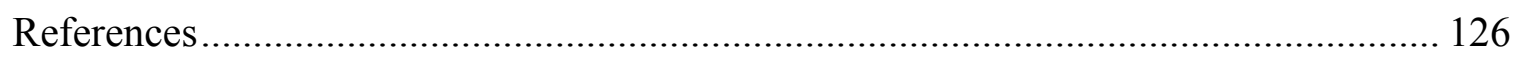

Appendix A: Initial e-mail sent to all my Brazilian contacts in my e-mail contact list.. 141

Appendix B: Interview Questions................................................................... 144 


\section{List of Tables}

Table 1: The Individualism Societal Norms ............................................................... 34

Table 2: The High-Context Communication (HCC) and Low-Context Communication

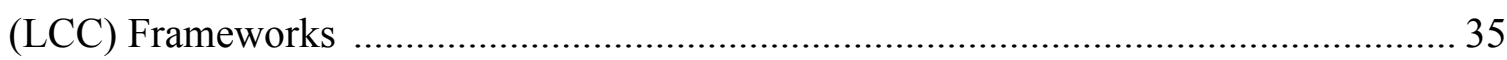




\section{Chapter 1: Cultural Behavior in Post-Urbanized Brazil: The Cordial Man and Intrafamilial Conflicts}

The purpose of this study is to explore whether Brazil's younger generation, raised during and after massive urbanization in the early 1970s and influenced by U.S. cultural globalization in the 1990 s, is experiencing a shift within the lowcontext/individualistic and the high-context/collectivistic spectrum-slowly moving from high towards low - and whether this shift is affecting intrafamilial dynamics between generations that identify with contrasting systems.

According to Edward T. Hall (1976), human interaction shaped by low-context (LC) communication occurs when the message conveyed to the receiver is explicitly manifested, mainly through words. The receiver is not expected to add contextual information such as structured moral rules of conduct, societal and religious expectations, social roles or pre-conceived behavioral norms. Conversely, human interaction shaped by high-context (HC) communication happens when part of the message being delivered is implicit, and words do not carry the same weight as the context does. The interpreter has the responsibility to decode the full message by reading cultural and nonverbal cues.

The contrast between LC and HC communication is illustrated by a scene in Alain Corneau's (2003) film Fear and Trembling, where there is a misunderstanding between a European woman-Amélie - and her Japanese boss. Amélie had been given verbal instructions, by her superior, Mr. Saito, to behave properly and to never speak to the president of the company. However, Amélie failed to comprehend the non-verbal cues inherent in Japanese society, especially with regard to the importance given to hierarchy. One morning, while serving coffee to executives of a sister company, Amélie greeted 
each person in perfect Japanese. After such incident, Amélie was reprimanded by her boss and asked to never speak Japanese again. The negotiation was called off since the executives did not feel safe to discuss secret matters in the presence of a Japanesespeaking foreigner. Amélie was immediately identified as an outsider.

Hall (1976) explains, "high-context cultures make greater distinctions between insiders and outsiders than low-context cultures do. People raised in high-context cultures expect more [knowledge of expected behavior] of others than do the participants in low-context systems" (p. 113). In the case presented in Fear and Trembling, despite Amélie's true desire to blend into Japanese society, her ignorance of cultural idiosyncrasies jeopardized her capacity to perform well in a Japanese company. "It is very seldom in Japan that someone will correct you or explain things to you. You are supposed to know, and they get quite upset when you don't” (Hall, 1976, p. 112). If this scene portrayed a Japanese woman greeting low-context executives, such as Americans executives, in their native language while she was serving coffee to them, one could assume that she might have been praised for her good knowledge of the English language, since "in the U.S. culture, we encourage individuals to 'sell themselves and boast about their achievements" " (Ting-Toomey \& Chung, 2005, p. 192).

“... [The purpose of using an example of a LC individual immersed in a HC culture is to illustrate that misunderstandings] are what happens when high- and lowcontext systems meet in the same setting, when the unspoken, unformulated, inexplicit rules governing how information is handled and how people interact and relate are at opposite ends of the scale" (Hall, 1976, p. 112). Therefore, conflict, heretofore defined 
as "an expressed struggle between at least two interdependent parties who perceive incompatible goals, scarce resources, and interference from others in achieving their goals" (Wimot \& Hocker, 2007, p. 9), easily emerges when the interacting parties identify with different systems.

Low-context systems present individualistic values, self-face concern, linear logic, and verbal-based understanding. In addition, its style is characterized as direct, person-oriented, self-enhancement and speaker-oriented. Countries such as Germany, Switzerland, the United States and Canada fall within this system. In contrast, highcontext systems have collectivistic and group-oriented values, mutual-face concern, spiral logic, and context-based understanding. Its style is characterized as indirect, statusoriented, self-effacing, and listener-oriented. Japan, Saudi Arabia, Latin American countries, and China embody the HC system (Ting-Toomey, 1999). Both systems are presented in more detail in the literature review chapter. While LC and HC characteristics are interchangeable with Geert Hofstede's (1980) work on individualistic and collectivistic societies, Hall's theory is more suitable to this research project due to its focus on communication patterns and cultural values, and its flexibility that allows a researcher to work with cultural differences on an individual level.

Although cultures are defined according to predominant characteristics as LC or HC systems, one should not assume every individual within a culture is consonant with the majority of the population. Cultures, subcultures and individuals occupy different positions on the $\mathrm{LC} / \mathrm{HC}$ spectrum and they also shift due to factors such as urbanization, 
economic development, and cultural globalization, as well as in different conversational situations where there is conflict or power imbalance.

Brazil is one of the countries that fall within the HC system and, along with its neighbors in Latin America, has undergone dramatic economic and social changes due to massive urbanization in the 1970 s and accentuated globalization with the end of the Cold War. In this study, Sérgio Buarque de Holanda's theory of the cordial man illustrates qualities of high-context Brazilian culture. These qualities are examined and evaluated from the perspective of intergenerational dyads that have been exposed to an urbanized and globalized environment in order to determine whether and how a shift from $\mathrm{HC}$ to LC is occurring.

According to Hall (1976), "the level of context determines everything about the nature of the communication and is the foundation on which all subsequent behavior rests (including symbolic behavior)" (p. 92). Therefore, the concept of high-context Brazilian culture described in this paper not only refers to the way people communicate with one another (verbally or silently), it also encompasses cultural behaviors such as rationality versus emotion, individuality versus collectivism, straightforwardness versus indirectness, and trust in self versus trust in the community. This is reflected via Brazil's diverse and mixed society, in terms of its founding cultures and peoples. Brazil's miscegenation encompasses a variety of stereotypes, including: the Portuguese emotional lyricism as an influence for the emotional tone permeating relationships; the innocence of the indigenous Indians leading to the trusting human nature; and, the forced compliance of African slaves, influential in the artificial pleasing nature. They shaped what 
superficially seems to be the cultural identity of a nation. These stereotypes prompted the Brazilian poet Ribeiro Couto (1932) to informally conceptualize the cordial man. Briefly, Couto described the cordial man as "hospitable and filled with credulity" (p. 3), which referred to Latin American people and their tendency to expose their emotions and cordiality when interacting with others, in contrast to European suspicion and selfishness (1932).

It was not until 1936 that Holanda (1995) provided the notion of the cordial man with a theoretical foundation based on a purely Brazilian perspective. Couto and Holanda agree on the existence of an overflow of emotions and cordial behavior, such as hospitality, generosity and delicacy of treatment, permeating communication and interpersonal relationships in Brazil. However, while Couto believes that these traits defined the cordial man and were genuine, Holanda argues that such traits served the practical purpose of concealing the cordial man's real intentions, since interactions can be cordial even when the underlying drift is the opposite. Basing his argument on the etymology of cordial, derived from the "Latin cordis and means heartfelt" (Rocha, 2003, p. 207), Holanda explains that cordiality not only encompasses congenial feelings, it also permeates interactions based on disagreeable feelings. Therefore, Holanda argues that cordiality, in Brazil, is a set of mannerisms used to obtain what is desired and to protect an individual from showing his true feelings and intentions when they are not in accordance with the high-context cultural, societal and familial expectations. "To the cordial man, life within society is, in a certain way, a real liberation from his fear of living with himself, of counting on himself in every circumstance of his existence.... It is 
like a life lived through others" (Holanda, 1995, p. 147). Thus, if the cordial man, born in the bosom of rural and patriarchal family tradition, can only navigate within society without being ostracized and thrive by maintaining the customary norms of conduct expected by his and older generations, can he survive in an urbanized and culturally globalized society influenced by individualism and other low-context characteristics?

This thesis focuses on the Holanda's version of cordial man, and not on Couto's interpretation. To this date, both definitions still cause confusion among writers and scholars. The word cordial, as popularly used in the Brazilian-Portuguese vocabulary, is directly connected to the behaviors Couto describes, such as welcoming, pleasant, and polite. For a Brazilian to read Holanda's theory, one must be prepared for critical selfreflection on virtuous cultural behaviors.

Due to its profound relevance and influence as a sociological paradigm that mirrors certain aspects of the Brazilian society, Holanda's theory has been studied and connected to various disciplines, including history by Ronaldo Vainfas (Colonização, Miscigenação e Questão Racial: Notas Sobre Equívocos e Tabus da Historiografia Brasileira [Colonization, Miscegenation and Racial Matters: Notes About Errors and Taboos of Brazilian Historiography], 1999); sociology by Antônio Cândido (Sérgio Buarque de Holanda e o Brasil [Sérgio Buarque de Holanda and Brazil], 1998); language and literature by Fred Ellison (Alfonso Reyes e Ribeiro Couto: Uma Correspondência Cordial [Alfonso Reyes and Ribeiro Couto: A Cordial Correspondence], 1984); Oswald de Andrade (Do Pau-Brasil à Antropofagia e às Utopias [From Brazil wood to Anthropophagi and Utopias], 1978); and, João Cezar de Castro Rocha (O Exílio do 
Homem Cordial [The Exile of the Cordial Man], 2004). However, there are no studies relating the cordial man, as a representation of a high-context element of the Brazilian society, to intrafamilial and intergenerational conflict.

This study aims to augment information about intrafamilial conflict due to the use of different communication styles and context assimilation. Mediators, facilitators, counselors and therapists can utilize the information gathered here to work with families in conflict who present the same patterns of behavior. In addition, scholars of various disciplines who are interested in Holanda's cordial man can be exposed to the field of conflict resolution, which is not yet a well-known field in Brazil. There is also a hope that the participants of this study will benefit from engaging in a reflective thought process while telling their stories and gaining new perspective regarding their intrafamilial conflicts. This research project poses three principle questions. First, is Brazil's younger generation-born or raised after massive urbanization in the early 1970s and influenced by U.S. cultural globalization in the 1990s-experiencing a shift within the LC/HC spectrum? Second, does this shift affect intrafamilial relationships between generations that identify with different systems? Finally, who is the cordial man now and can he adapt to a world that is becoming more dissimilar to his rural and patriarchal native habitat?

\section{Research Design}

There are no studies relating the cordial man, as a representation of a high-context element of the Brazilian society, to intrafamilial and intergenerational conflict. Therefore, in this qualitative study, grounded theory was the strategy of inquiry, since 
according to Strauss and Corbin (1990, p. 23) "one does not begin with a theory, then prove it. Rather, one begins with an area of study and what is relevant to that area is allowed to emerge." Building on a literature review of academic research on the roots of the cordial man, high- and low-context systems, urbanization and cultural globalization, I conducted a qualitative study aiming to develop a theory. Data was collected through interviews with semi-structured open-ended questions. I interviewed five father-son dyads about their experiences and opinions regarding intrafamilial dynamics, discipline methods for children, impact of globalization on conflict management and relationship between father and son. Their responses, guided by their value system, were helpful in revealing how group-oriented or individualistic these values were and if the cordial man behavior was also present in the intimacy of their homes. The gender of the participants was chosen based on the use of the word man in the term cordial man.

The balance of the thesis is composed of chapters two through seven. Chapter 2 explores the role and biases of the researcher. I address my interest in this topic and share valuable experiences, including any personal idiosyncratic beliefs that could have affected the study. Chapters 3 and 4 contain the literature review, in which different works are commingled in order to create a theoretical foundation that addresses the research questions of this study, with chapter 4 particularly focused on intercultural communication in Brazil. Chapter 5 explores the methodology of this research, by first reviewing the research questions and how it relates to the methodology. I also clarify the purpose for choosing grounded theory as the strategy of inquiry. I then outline the design of the study and describe the data collection method, the sample size, population and the 
main data analysis techniques employed in the research. Finally, the validity, reliability and generalization of the study are addressed. Chapter 6 discusses the findings through thematic analysis. The final and seventh chapter identifies the limitations of the study and offers recommendations for further research.

As humans strive to communicate in order to meet their needs and minimize the occurrence of conflict, it is paramount to understand individual and social communication patterns and systems. The theory of low- and high-context societies illuminates the reasons people behave and communicate differently. Japan, being at the upper extreme of the high-context scale, illustrated how conflict can develop when LC and HC individuals meet in the same setting. Brazil, another HC culture, has been more flexible throughout the years with its moral and societal values than Japan; therefore, Brazil occupies a less extreme position in the HC scale when compared to Japan. As cultures do not occupy a steady position in the $\mathrm{LC} / \mathrm{HC}$ scale, there is a need to understand if Brazil is shifting from $\mathrm{HC}$ to $\mathrm{LC}$ due to urbanization, globalization and the absorption of individualistic values by the younger generation. If this shift is happening, conflict between generations that identify with different systems may also be happening and former values considered virtuous may be becoming outdated. 


\section{Chapter 2: Personal Stance}

My first encounter with the concept of collectivistic/high-context and individualistic/low-context cultures was puzzling. I recall feeling uneasy about learning that my native Brazil was considered, alongside other Latin American and Asian countries, a HC culture. At that point, I did not understand that countries, cultures, individuals and situations occupied different positions in the $\mathrm{LC} / \mathrm{HC}$ scale, nor did I understand that this concept was created to explain cultural patterns that people choose to express in most situations and not in all of them. At that time, I was confident that there was something wrong with this theory. How could ritualistic Japan, formal Mexico and relaxed and welcoming Brazil all fall within the same category?

As my understanding of Hall's (1976) theory of HC cultures deepened, I became aware that Brazil occupied a lower position in the HC context scale when compared to countries like Japan and I needed to understand why. I initially thought that the legacy from the colonization period had implications on the cultural behavior of societies. On the one hand, the U.S. had a developmental colonization, such that the colonizers were hoping to develop the land in order to succeed. Their goals, mainly based on Calvinist Protestant values, focused on personal growth and individualism. On the other hand, Brazil had an exploitative colonization; the settlers were interested in collecting wealth to be invested in Portugal. Native Brazilians were converted to Catholicism, which emphasizes feelings of remorse, guilt and shame.

Ribeiro (2000), when discussing the formation of the Brazilian civilization, notes that upon the arrival of the caravels to the new land, Portuguese colonizers encountered 
native inhabitants on the coast of Brazil and were bewildered by their beauty and innocence, but were also terrified by their demoniac and anthropophagic rituals and uninhibited sexual practices. Apart from being a source of labor and sex to the colonizers, the native Indians became a target for forced religious indoctrination, which modified the way the natives perceived the world around them and made familiar behaviors seem wrong and out of synch with the catholic goal of salvation.

Although comparative colonization seemed an interesting starting point to partially explain the diverging communication patterns developed in different societies, I decided I wanted to stay closer to home. I began noticing that my father, more often than not, chooses to communicate through $\mathrm{HC}$ means, such as delivering indirect messages, more than his daughters do. Additionally, he is the one who worries the most about the image of his family. I wondered if the same was happening to other Brazilian familieswhere parents identify themselves with the HC system while their children shift towards a more LC approach.

One day, while talking to my father on the phone, I asked for advice concerning a family with whom I had been working as their family coach. There was a male teen involved with gangs and alcohol and his father was displeased with such behavior. Their connection was damaged and the father was only willing to reconnect based on the condition of behavioral changes. I asked my father what he would do, to which he promptly replied: "I would not try to tell him directly what to do. Instead, I would try to make him feel bad. I would tell him: Do you really want to disappoint me? Do you really want to make me sad?" I translated this response as emotional manipulation. As 
we finished the conversation, I was left with feelings of anger and surprise. There it was; the confirmation of what he had done successfully over the years to control me without really engaging in a productive conflict, without giving me logical explanations for matters that were questionable to me. The surprise came from the fact that once he explicitly told me his disciplinary method of choice, he implicitly affirmed that he was aware of how effective it was in raising me. I saw in him the cordial man described by Holanda (1995). He was using his calm and loving —or cordial—manners to mask his real intention of convincing me to do what he thought was the best for me. Instead of convincing me to act differently by giving me rational motives that would allow me to decide for myself, he blinded my ability to think by making me feel guilty for hurting his feelings, even though my actions did not affect him directly and were only affecting me. Although my father learned to use his emotions in a strategic way, I knew his reactions were based on genuine emotions in response to my actions. Thus, it was very difficult for me to separate rational from emotional reasoning when dealing with my father since his emotions were important to me and needed to be considered.

As I was growing up, it was paramount to my family to maintain the "structured family" appearance and to be considered honorable above all else, like a good highcontext family should. My siblings and I made few choices that disappointed my parents, since before we acted, even as adults, we had to think about how my father would handle the shame and the deception. As the cordial man described by Holanda (1995), it was my father's choice to live his life and control our lives according to the morals and rules 
of conduct of the group we were a part of, even when these rules did not represent what we wanted as individuals.

While I went to graduate school in the United States, I felt it was easier to make choices based solely on my needs and wants. I still thought about how these choices would affect people around me and I pondered before I acted. Nevertheless, to this date, I still have to remember that I am the one responsible for actions and that my choices may not please everyone at all times. My one-year experience in the U.S. as an adolescent exchange student taught me that not all families are like mine. In the United States, the concept of individuality and privacy is highly regarded, as many parents help their 18 year olds slowly transition from their protective shelter to a life of independence and responsibility.

I still regard my father as the cordial man who now faces intrafamilial dilemmas brought by his children who were molded by an urban and culturally globalized society. One of the reasons that compelled me to pursue this research topic is the fact that I, being 10 years younger than my siblings, have seen the changes in the cordial man of our family, and these changes have not come about without major conflicts. Therefore, I wondered if there are other families experiencing conflicts that stem from a patriarchal figure being challenged by lower-context children.

My experiences with a cordial man as my father made me emotionally invested in this study. However, throughout the process I was aware of my subjectivity and maintained a critical view in all directions. I was committed to performing constant 
revision of my own biases and to abide by a set of procedures guided by grounded theory to ensure objectivity while coding and explaining data retrieved from subjects.

As a Brazilian, I was also aware that is more difficult to be critical of customs and rules of conduct of a high-context society that has contributed to my personal view of the world. Then, again, I aimed at being a neutral observer, knowing that cultures should not be viewed dichotomously. My experience abroad expanded my horizon on the differences between both cultures, which would not be possible if I had not left my comfort zone in Brazil. My international experience in a low-context culture gave me the lens I needed to keep my biases at a safe distance.

The cordial man is a well-known concept for historians, philosophers, anthropologists and sociologists in Brazil. Nonetheless, it has not been connected yet to the family arena. My interest in family conflicts stems from two factors: I am part of a large caring family and, therefore, family values are paramount to me; and, I have worked with struggling families as a family therapist.

For several years, in-home family mediation occupied an important role in my life and it also influenced my decision to focus on family dynamics as the subject of this study. My professional training and interpersonal skills were positive attributes that I brought to this research. I am accustomed to listening to people recount their experiences with pain, deception, hatred, acts of horror and negative feelings without being judgmental or pitying. I am empathetic but I strive to remain neutral. Interviewing the subjects of this study in their homes was as comfortable to me as it was going to work every day. I also strived to connect with the families I interviewed in the same way that I 
connected with the families that I used to work with - by being open, honest and respectful. Reminiscing about my own high-context experiences gave me insight into other families' experiences and helped me to understand differences in communication patterns and how these disparities lead to conflict. By believing that I was emotionally invested in this study, I chose to be aware of my subjectivity instead of pretending it did not exist. I followed the premise that subjectivity is a “... unique, useful, personal quality of a researcher" (Jansen \& Peshkin, 1992, p. 682). We are only capable of explaining the world outside by reflecting on our own experiences. As Dilthey (Jansen \& Peshkin, 1992, p. 690) claims: “Of course we know nothing about any real world which lies outside of our consciousness. We know of reality (i.e., an external world) only insofar as our will and our positing of goals are determined." My experience as a part of a family system has sculpted the way I perceive the world and because I am conscious of that I make a constant effort to put my perceptions aside so I can absorb what is still foreign to me. 


\section{Chapter 3: Review of the Literature I: Intercultural communication}

This chapter interweaves literature pertinent to cultural variability and intercultural communication. Concepts found in relevant literature are synthesized and interlaced to create a theoretical foundation that sustains the development of the proposed research. First, the concept of cultural variability is explained. Second, two important cultural variability frameworks_- being one of them Hall's low-context/high-context approach — are examined and compared in order to explain the researcher's choice to work with Hall's theoretical model. Then, the two attributes from Hall's theory that are important to this research are examined: the ability to work with the concept of $\mathrm{LC} / \mathrm{HC}$ on an individual level and the relationship between communication patterns and cultural behavior.

\section{Cultural Variability}

Hall (1976) states: "One of the functions of culture is to provide a highly selective screen between man and the outside world. In its many forms, culture therefore designates what we pay attention to and what we ignore" (p. 85). The process that one goes through to acquire a mother tongue is similar to the process of learning and being a part of his or her native cultural habitat, in the sense that, generally, no major effort has to be made for both of these acquisitions to take place. As it is with language, culture is naturally learned by observation and repetition at early stages of childhood. As the individual matures and intellectually develops, the environment in which this individual is immersed emits a series of approving or disapproving signals. When a word is pronounced properly or a behavior is displayed according to the rules of what is 
considered socially expected within the group, the child is encouraged to progress in this same direction. Otherwise, what others view as wrong or inappropriate restrains the impulses of the child.

Differences in the way people's minds are culturally and collectively programmed is what allows for cultural variation to occur between different groups, as well as among members of the same group (Hofstede, 1991). Cultural variation has ignited the curiosity of a multidisciplinary and theoretically diverse group of researchers. Some from more obvious fields such as anthropology (Hofstede, 1980; Hofstede, Neuijen, Ohavy, \& Sanders, 1990; Hofstede, 1991; Hofstede, 2001), psychology (McCrae \& Terraciano, Personality profiles of cultures: Aggregate personality traits, 2005), conflict resolution (Rummel, 1966), business management (Fang, 2003), ethology (Van Der Vliert, Schwartz, Huismans, Hofstede, \& Daan, 1999), marketing (Brodowsky, Granitz, \& Anderson, 2008), languages (Kowner \& Wiseman, 2003); and others from fields where cultural variation is not the most common focus of research such as nursing (Eubanks, McFarland, Mixer, Munoz, Pacquiao, \& Wenger, 2010), medicine (Hallenback, 2006; Torres \& Rao, 2007) and information technology (Usunier \& Roulin, 2010).

Different frameworks have been developed to understand values across different cultural groups. Two of these frameworks are widely known and are considered landmarks in the study of intercultural relations. For comparative purposes, both frameworks will be introduced in this study in order to clarify their similarities and differences and to justify the researcher's preference for using the first approach. The first framework is Hall's (1976) work on the relationship between communication 
patterns and cultural values, specifically the low-/high-context approach and, the second is Hofstede's (1980) cross cultural work-related value dimensions, specifically the individualism-collectivism dimension.

Low-Context and High-Context Systems. Hall's work on concepts such as time, nonverbal language and context has popularized and conceptualized the idea of intercultural communication (Leeds-Hurwitz, 1990; Rogers, Hart, \& Miike, 2002). Before introducing the concept of low- and high-context systems, Hall (1976) introspects the feelings of instability and information overload that westerners, including himself, experience in modern days. He warns that if westerners, who mostly function in a LC system, want to cope with a complex, fast-paced, and information-processing way of living, they must understand that there are other ways of creating reality. If westerners want to deal with the inability to keep up and process changes and new data, they must learn to use the context in which they are immersed to gather information, relying more on a holistic approach than a compartmentalized view of a given process.

Context "refers to the nature of how meaning is constructed differently across cultures using different ratios of context and information” (Kittler, Rygl, \& Mackinnon, 2011, p. 65). Throughout his book, the reader is challenged to reevaluate his/her own cultural framing to understand how others perceive the world. Hall (1976) states that "It is important for the reader to come to grips with his own model of culture in its manifest as well as its latent forms, because my purpose is to raise some of the latent to conscious awareness and to give it to form so that it can be dealt with" (p. 16). 
Although cultural observations seem to demonstrate the author's admiration for a system that is different from his own, he also outlines problems faced by people living in high-context systems, such as the slow-moving bureaucracy and the importance of political connections in the public administration environment, such as the case of Brazil. Hall (1976) recalls that one system is not better than the other and that his intention is to delineate their differences and congruencies.

Hall suggests that individuals combine preprogrammed culture-specific contexts and information in different proportions to create meaning (Kittler, Rygl, \& Mackinnon, 2011). When describing some of the attributes that define low- and high-context systems, Hall (1976) notes that LC systems are prone to constant changes; therefore, they can be unstable. People in LC systems exchange information in an explicit manner and do not need to spend much time interpreting what is left implicit by the interlocutor, since it is not expected of him/her to decode what the other person is really thinking. Lowcontext people are expected to take responsibility for their actions and are less prone to ostracizing individuals who do not belong to the same cultural group. They also have a tendency to compartmentalize several aspects of their daily lives: from their relationship with time to the linear way information is processed.

Conversely, high-context systems are slow to change, and thus more stable. People in HC systems are preprogrammed to notice contextual information, thus are more equipped to understand beyond what is being said through words and "read between the lines." High-context people are more prone to taking responsibility for actions performed by those who are dependent on them, either in the family or professional realm, and are 
more discriminative of outsiders. Their way of thinking, instead of being logically linear, is more comprehensive, and their relationship to time is less valued than their relationship with people. Thus, HC people would rather choose to be late than leaving an activity unfinished or a person in need.

Hall (1976) utilizes a writing style that may be considered informal and empirical. His cultural observations draw from his own experience living with the Navajos and his research on different cultural systems. He builds his conceptual framework on contrasting information gathered from the same issues present in LC/HC-systems. He claims, "while I do not exclude philosophical systems, religion, social organization, language, moral values, art and material culture, I feel it is more important to look at the way things are actually put together than at theories" (p. 16). While Hall (1976) chooses to approach cultural differences between LC and HC systems in a descriptive manner, Ting-Toomey (1999) summarizes Hall's work by creating dimensions that are representative of both systems. In order to fully understand the LC/HC concept, we use Ting-Toomey's (1999) dimensions in the following subsections.

\section{Low-context systems. According to Ting-Toomey (Communicating Across}

Cultures, 1999), people from a low-context culture, in most situations, choose to exhibit the following traits when interacting with others: individual values, self-face concern, linear logic, direct style, person-oriented style, self-enhancement style, speaker-oriented style and verbal-based understanding. People with individualistic values favor freedom of action based on individual needs over collective needs. Independence and selfreliance are relevant concepts to this individual. Poasa, Mallinckrodt, and Suzuki (2000) 
affirm, "individualistic people define their sense of self according to how they are different from others" (p. 33). Cultural, moral, behavioral or aesthetical differences are welcomed and respected in this system.

Self-face concerns can be exemplified through a situation in which loss of face is imminent. The low-context communicator is solely responsible for his actions and not for the actions of others. Thus, if honor and integrity are in jeopardy, the person is likely act on it, even if this means the loss of face to others. Relationships due to moral disagreements or other differences are terminated without relevant social consequences.

Individuals using linear logic have a tendency to believe only what they observe and perceive as truth. When attempting to give meaning to ideas, expressions or events, the individual moves precisely from one point to the next using selected pieces of information without considering complementary data and inputs which would allow for a more comprehensive and inclusive outcome. To have a direct style means that individuals choose to be assertive in most situations. Eye contact and objectivity are valued, since they aim for straightforwardness. A person-oriented style regards hierarchy loosely. When interacting with people, rituals and ceremonies are avoided since people ought to be treated equally and respected for their individuality. "Low-context cultures value facts and 'hard data', that is, statistics, quantitative information and absolute, objective truths.... People from low-context cultures admire candor and directness" (Dozier, Husted, \& McMahon, 1998, p. 113).

The self-enhancement style is common in some LC cultures in which individuals are rewarded for highlighting their accomplishments. In societies where vocal inputs are 
valued rather than tacit perception and observation, people may have the desire to appear strong, eloquent, and capable. According to Sedikides and Gregg (2008), one of the characteristics of self-enhancement is that people tend to inflate their abilities, such as in the case of "university students in the U.S. and Europe [which] regard themselves as above-average drivers (Svenson, 1981), and even drivers hospitalized after causing accidents persist in believing they are no worse than regular drivers (Preston \& Harris, 1965)" (p. 104).

The speaker-oriented style emphasizes rhetoric. The act of speaking is, usually, more important than listening. In a case I had as a family coach, an American school recommended my services to a girl, whose family was of Mexican heritage, due to her lack of verbal input in the classroom. This girl, Silvia, received good grades and was capable of focusing on tasks while in the classroom. She was bullied by her peers and misunderstood by her teachers due to her shyness and quiet manners. As I began to work with the family and look for signs of family conflict, trauma or abuse, I learned that she had a tightly knit family who happened to be very quiet. During our sessions, family members were concise in speech and often used nonverbal messages. Silvia demonstrated to be at ease while in the company of her family and laughed often while we played family games. The conclusion was that Silvia, who had moved to the US when she was 7 , was experiencing a cultural shock within a low-context school. She was accustomed to speak less and listen more.

Finally, verbal-based understanding refers to the message's denotation that is regarded as the most relevant information to be processed and considered. What is said is 
what counts and there are no expectations between the communicating parties that implicit messages must be decoded. The German, Swiss and North American cultures represent, at different levels on the LC scale, the styles described above.

Pekerti and Thomas (2003) examined the communication styles of East Asians and Anglo-European New Zealanders. Ninety-six students (48 representing the Asian sample and 48 representing the Anglo-European sample) participated in the study. Results showed that Anglo-Europeans, mostly New Zealanders, Europeans and North Americans displayed more idiocentric behavior when communicating to Asians. AngloEuropeans were by far more expressive, dominant, aggressive, preoccupied with finishing the task given, opinionated and logical. Asians, mostly Chinese, scored high on being more accommodating, averted to argument and more inclined to shift opinion. The idiocentric behavior found by Pekerti and Thomas (2003), when examining people from low-context cultures, is congruent with the following dimensions developed by TingToomey (1999): individualism, linear logic, and direct and speaker-oriented styles.

In another study, Croucher et al (2012) investigated the relationship between national cultures and conflict styles. The sample included 1,972 individuals (657 from India, 311 from Ireland, 232 from Thailand and 592 from the United States). Results confirmed, in accordance with Hall (1976) and Ting-Toomey (1999; 2005), participants from LC nations (the U.S. and Ireland) prefer to put their interests ahead of others in conflicting situations when compared to HC individuals. Additionally, HC nations (India and Thailand) prefer to withdraw from conflict to maintain harmony and will sacrifice 
their needs for the needs of others. Their findings also coincide with the dimensions of individualism and self-face concern.

Interestingly, against previous research, Croucher et al (2012) found that HC individuals were more inclined to compromise and conciliate diverging interests than LC individuals. The authors speculate that this shift might be due to the growing economies of India and Thailand, and the possible acquisition of individualistic values. These speculations are directly related to this study, since the effects of urbanization and globalization in Brazil are analyzed in order to determine its relationship to a possible cultural shift among younger Brazilians.

High-context systems. HC cultures display the following behavior: grouporiented values, mutual-face concern, spiral logic, indirect style, status-oriented style, self-effacement style, listener-oriented style and context-based understanding. Grouporiented values refer to individuals who consider social, moral, religious and cultural norms of their family, group and society before reaching a decision or taking action. People with group-oriented values define themselves in terms of their relationship to others and choose not to separate their individual selves from their group.

Mutual-face concern can be found in situations where two individuals or families are engaged in a conflict that involves shame, honor or loss of face. This impasse tends to yield partial benefits to both parties and saves face within the environment they are in. Even when the outcome of the conflict does not please everyone, the ultimate goal is to preserve relationships intact. Facts are not as important as the outcome. 
In a high-context culture such as Spain, there is a "public truth" which preserves everyone's face, and the "real truth" which is understood by all, but not verbalized. Among people of the same high-context culture, there is little confusion between the public truth and the real truth. The meaning of the message is interpreted in light of the context of the parties' relationship. (Dozier, Husted, \& McMahon, 1998, p. 114)

Spiral logic is the ignition of a thought process to give meaning to ideas or facts, which in most cases considers information acquired holistically. This style of logic emphasizes the importance of gathering information from multiple sources, rather than from fragmented parts.

The indirect communication style occurs when there is a great power distance between the interacting parties or when there is a need to express discontent or disappointment. The message is cautiously and indirectly expressed. The sender uses selective words to guide the receiver to the point; however, it is the listener's responsibility to understand the cues and decipher the connotation behind the message. Indirect communication serves diverse purposes in $\mathrm{HC}$ cultures, especially in Brazil. On the positive spectrum, indirect communication empowers the listener since he/she is responsible for decoding the message, it helps the involved parties to maintain face, and it can give a friendly tone to any sort of conversation, thus keeping harmony at all costs. Conversely, indirect communication can be dubious and generate confusion; it may be understood as dishonest and it may fail to deliver messages of great relevance and urgency in a non-ambiguous way. When $\mathrm{HC}$ indirect communication is combined with 
status-oriented values, or high power distance, in a LC setting, the consequences may be lethal. The case of Avianca-052's airplane crash, which is addressed at the end of this section, is an unfortunate illustration of cultural unawareness between a HC and a LC communicator.

The status-oriented style highly regards hierarchical respect and obedience. Generally, relationships are based on power, demand formality, and the utilization of adequate rhetoric to emphasize the power distance. In Brazil though, formality is avoided as often as possible since individuals will try to narrow the distance between them, including strangers, through the use of diminutives and by attempting to create a superficial personal connection with one another. Thus, Brazil confirms Hall's theory regarding the existence of great power distance in $\mathrm{HC}$ cultures. However, Brazilians try to behave in an informal manner to navigate within such a socially discriminative system.

The self-effacement style can be perceived in a professional or social situation, when an individual does not divulge his/her accomplishments knowing that others will realize them based on the results. When one is praised in public, the compliments are received with humility and embarrassment. The receiver then reassures the speaker that, circumstances, such as collaboration from peers, guidance from superior and wisdom of family members contributed to his or her success.

The listener-oriented style is when listening is considered an act of wisdom, since one always learns from others' experiences. Silence between sentences is also perceived as a needed pause to reconnect with the inner self. 
Context-based understanding means that communication bases itself not only in what is being said, but also in what can be read "between the lines." The connotation of the message is highly valued and it is used to comprehend the entire communication. Japan, China, Brazil and Thailand are some of the countries that well represent this characteristic in the HC system.

In a study by Poasa et al. (2000), 73 students were surveyed (23 U.S. Americans, 25 American Samoans and 25 Western Samoans) regarding their individualistic/collectivistic cultural beliefs and their attributions about family problems and resolutions. Qualitative findings confirm that Samoan students share collective cultural beliefs, while American students share individualistic cultural beliefs. Five themes emerged that are interchangeable with Ting-Toomey's (1999) high-context dimensions: spiral logic, status-oriented style, group-oriented values, indirect style and mutual-face concern. More specifically, the findings show that:

... (b) Samoan students tend to distribute attributions of blame in a nonlinear fashion and view family problems as having multiple causes; (c) Samoan students' responses emphasized the influence of social status and power hierarchy differences - they used the word should very frequently and placed more blame on high-status actors who failed to conform to the social obligations of their role, whereas they tended to absolve low-status actors from blame; (d) in-group/outgroup status was very important to Samoan students, in part because the actions of in-group members were viewed as reflecting directly on themselves; (e) when Samoan students did voice attributions of blame to an individual (especially to 
high-status, in-group actors), they used third-person grammatical constructions or abstracted references to general religious or legal proscriptions that tended to insulate them from a direct, person-to-person expression of blame; (f) Samoan students suggested resolutions for problems targeted at external, situation-specific aspects and resolutions with the goal of preserving relationship harmony. (p. 52) An example of cultural variation in a multicultural society can be found in a qualitative study regarding cultural differences in self-enhancing versus self-effacing perspectives, in which Suzuki, Davis, and Greenfield (2008) observed and read the journals of 34 American high school students that were representative of four major ethnic groups: African-Americans, Asian-Americans, Euro-Americans and Latin Americans. The study aimed at understanding if students interpreted praise or criticism in a self-enhancing or self-effacing manner. Results show that Euro-Americans and African-Americans displayed a self-enhancing (low-context) frame of reference, while Asian American and Latin American participants shared a more self-effacing (highcontext) perspective. Tammy, an African-American volleyball player, after winning the "Most Valuable Player" award, writes in her diary, "All I know is that I earned my trophy and I'm very proud of it and myself... Smiling, people adoring you, getting awards and walking in front of hundreds of parents, it just felt good" (p. 88). Conversely, Nicole, a second-generation Korean-American player, who was also disputing the same award with Tammy, writes, "I kind of didn't like it when people told me that I'll be the MVP because I didn't know how to respond.... I find myself afraid of what others might think of me. I don't want to have the reputation of being conceited in any way" (p. 88). 
Suzuki, Davis, and Greenfield (2008) recall that cultural variability studies are not constrained to cross-national investigations. Currently, cultural differences are not a matter of interest of governments or businesses alone. Educational institutions, religious settings, neighborhoods and even families must be prepared to respond appropriately to cultural differences and conflicts.

In order to illustrate the serious consequences that may originate from unsuccessful communication between LC and HC individuals, the plane crash of Avianca-052 will be briefly examined. Malcolm Gladwell (2008) explores the surrounding phenomena that enable successful outcomes in diverse arenas. In the book Outliers: The Story of Success, Gladwell reviews the relationship between plane crashes and cultural values to show how Korean Air turned itself around and became a successful enterprise after several accidents. Based on an investigative process performed by Korean Air, it was concluded that cultural values, such as power distance, played a major role in times of crisis. First officers and flight engineers were having difficulty in pointing out mistakes that were being made by pilots, their superiors, in situations of crises, ultimately leading to disaster.

In the study Culture in the Cockpit: Do Hofstede's Dimensions Replicate?, Helmreich and Merritt (2000) measured the Power Distance Index of pilots worldwide and ranked South Korea the second highest, following Brazil. In 1990, Avianca-052, a Colombian airplane, was flying in adverse weather conditions to New York (JFK). Air traffic control was holding up 716 airplanes upon landing. As a standard procedure, all airplanes arriving at their destination should have a small quantity of fuel since its fuel 
tanks need to be almost empty to ease the landing process. Thus, all airplanes that were being held up near JFK were concerned with the amount of fuel they had and for how long it would last. It was no different with Avianca-052. It was held up for one hour and seventeen minutes until its engines stopped due to the lack of fuel. Although weather and minor malfunction in the airplane were a problem, there was evidence that the pilot was tired and the communication between the Colombian pilot and the Colombian first officer, and between the Colombian first officer and the American air traffic control officer were the main causes of the crash (Gladwell, 2008).

According to Gladwell (2008), the pilot had been working for more than 12 hours and was, at that instance, operating an older airplane that required extreme physical strength, thus he began to make minor mistakes that affected his decision-making abilities. His first officer, also from Colombia, which is a high power-distance and status-oriented society, not only expected clear orders from his superior, but also failed, out of respect, to suggest alternatives that could have saved their lives, keeping quiet most of the recorded time. Besides the fact that the pilot had clouded judgment and both workers were unable to communicate in a direct and equal manner, a third aspect contributed to the unfortunate outcome: the misunderstandings between a high-context Colombian and a low-context American professional. Throughout the several instances when Klotz, the first officer, attempted to communicate that they were running out of fuel, he only used mitigated speech to convey the urgency of their situation and was unable to be assertive, positioning himself in a lower-rank position compared to the airtraffic controller, who sounded too direct and intimidating to Klotz. Based on an 
investigative report, Gladwell concludes that the air traffic controller did not understand the urgency of the matter since Klotz only spoke in a calm manner about fuel, and since everyone in that situation was running out of fuel, the controller was unable to decode Klotz's message. The shocking and saddening part of this communication disaster is that just minutes before the crash, the pilot asks Klotz, one last time, about the response the control tower had given him regarding their fuel situation, to which Klotz solely responds: "the guy is angry."

Hall's work on LC/HC cultures allows us to contrast cultural values and behaviors. Due to the similarities found in Hofstede's work on individualistic and collectivistic cultures and Hall's LC/HC cultures, Hofstede's work is presented in the next section as well as an explanation as to why his theoretical model was discarded as the most suitable approach for this thesis.

Individualism-collectivism dimension. Geert Hofstede’s (1980) “Culture’s Consequences" is an influential work in the study of cross-cultural management. After surveying a total of 116,000 managers and employees of a large multinational corporation with subsidiaries in 50 countries and 3 regions, Hofstede $(1980,1991)$ identified four organizational value patterns across a diverse range of cultures. First, individualism-collectivism, as the most relevant dimension, measures if a national culture was more inclined to emphasize individual needs before group needs, or vice-versa. Second, power distance assesses the tolerance individuals had towards the inequality of power distribution. The third dimension, uncertainty avoidance, considers people's relationship with ambiguity, and the fourth dimension, masculinity-femininity, gauges the 
interchangeability or inflexibility of a society toward sexual roles. In a later research project (Chinese Culture Connection, 1987) Hofstede and his colleagues identified a fifth work-related dimension, which they called Confucian Dynamism due to its values stemming directly from the religious teachings of Confucius.

In order to identify the individualism-collectivism dimension, Hofstede (1980) interviewed employees utilizing questions such as:

1) Do you have challenging work to do-work from which you can get a personal sense of accomplishment? 2) Do you work with people who cooperate well with one another? 3) Do you have training opportunities (to improve your skills or learn new skills)? 4) Do you have considerable freedom to adapt your own approach to the job? 5) Do you have a good working relationship to your manager? 6) Do you have a job that leaves you sufficient time for your personal or family life? (Hofstede, 1980, p. 239).

After gathering data over forty countries, he then developed the Country Individualism Index (IDV), which basically “opposes in particular the importance of time for personal life on the high IDV side versus the importance of being trained by the company on the low IDV side" (Hofstede, 1980, p. 213). Coming from employees' organizational opinion toward IBM, Hofstede (1980) extrapolates the meaning of the data to other arenas of a nation state such as social, religious and ideological, as he claims below:

It also appears that IDV is correlated with several country-level indicators: it correlates 0.82 with GNP per capita, and also with geographical latitude, with the 
size of the HERMES [IBM] subsidiary, and with various characteristics of political and economic systems (such as occupational mobility, sectoral equality, and press freedom). From this, a picture of the Individualism-Collectivism dimension of societal norms can be drawn, as well as some inferences about its origins and consequences. The latter are separated into consequences (1) for society at large; (2) for religion, ideology, and theory; and (3) for organizations. (1980, p. 213)

Hofstede's main focus was the analysis of a cross-national cultural relationship between man and the organization that provided him with an income. He even warns his readers that the IDV "index is not suitable for distinguishing among occupations, sexes, age groups or individuals" (213). This study diverges from Hofstede's cross-national business-oriented analysis in the sense that its focus is on the cultural differences between fathers and sons, who identify with distinct cultural influences in a single country —in this case, Brazil. The impact of low-context/individualism versus highcontext/collectivism on an individual level within the family realm is at the center of this investigation.

Additionally, this study explores the relationship between cultural values and communication styles (Ting-Toomey, Communicating Across Cultures, 1999) suggested by Hall's (1976) approach. From the data collected through interviews with fathers and sons, this research seeks to grasp the underlying cultural values enmeshed in their low/high-context communication patterns. 
Although this research discards Hofstede's theory as the most suitable approach, due to its business-oriented origin and its inflexibility to be applied at an individual level, note that the social consequences drawn by Hofstede (1980), based on the IDV of a country, are interchangeable with Hall's (1976) description of low-context/high-context cultures.

The tables below, the first on Hofstede's (1980) individualistic-collectivistic approach and the second on Hall's LC/HC framework, show that both authors interpret and generalize cultural aspects of groups in a similar manner. While Hofstede describes social behavior of people based on their organizational values, Hall focuses on the way people communicate and he correlates their communication patterns to their individualistic-collectivistic values.

\section{Table 1: The Individualism Societal Norms}

\begin{tabular}{|c|c|}
\hline Low IDV & High IDV \\
\hline $\begin{array}{l}\text { In society, people are born into } \\
\text { extended families or clans which } \\
\text { protect them in exchange for loyalty }\end{array}$ & $\begin{array}{l}\text { In society, everyone is supposed to } \\
\text { take of him or herself and his or her } \\
\text { immediate family }\end{array}$ \\
\hline - "We" consciousness & - "I" consciousness \\
\hline - Collectivity-orientation & - Self-orientation \\
\hline - Identity is based on the social system & - Identity is based on the individual \\
\hline $\begin{array}{l}\text { Emotional dependence of individual } \\
\text { on organizations and institutions }\end{array}$ & $\begin{array}{l}\text { Emotional independence of } \\
\text { individual from organizations or } \\
\text { institutions }\end{array}$ \\
\hline $\begin{array}{l}\text { - Emphasis on belonging to } \\
\text { organization; membership ideal }\end{array}$ & $\begin{array}{l}\text { - Emphasis on individual initiatives } \\
\text { and achievement; leadership ideal }\end{array}$ \\
\hline $\begin{array}{l}\text { Private life is invaded by organizations } \\
\text { and clans to which one belongs; } \\
\text { opinions are predetermined }\end{array}$ & $\begin{array}{l}\text { - Everyone has a right on a private life } \\
\text { and opinion }\end{array}$ \\
\hline $\begin{array}{l}\text { - Expertise, order, duty, security by } \\
\text { organization or clan }\end{array}$ & $\begin{array}{l}\text { - Autonomy, variety, pleasure, } \\
\text { individual financial security }\end{array}$ \\
\hline
\end{tabular}


- $\quad$ Friendships predetermined by stable social relationships; but need for prestige within these relationships

- Belief in group decisions

- Value standards differ for ingroups and outgroups; particularism
- $\quad$ Need for specific friendships

- Belief in individual decisions

- Value standards should apply to all; universalism

Note: Table from Hofstede, Culture's Consequences: International differences in workrelated values, 1980, p. 213.

\section{Table 2: The High-Context Communication (HCC) and Low-Context}

\section{Communication (LCC) Frameworks}

\begin{tabular}{|c|c|}
\hline HCC characteristics & LCC characteristics \\
\hline - Group-oriented values & - $\quad$ Individualistic values \\
\hline - Mutual-face concern & - Self-face concern \\
\hline - $\quad$ Spiral logic & - Linear logic \\
\hline - Indirect style & - Direct Style \\
\hline - Status-oriented style & - Person-oriented style \\
\hline - Self-effacement style & - Self-enhancement style \\
\hline - Listener-oriented style & - Speaker-oriented style \\
\hline - Context-based & - Verbal-based understanding \\
\hline
\end{tabular}

Note: Table from Ting-Toomey, Communicating Across Cultures, 1999, p. 101.

In line with Gudykunst, Ting-Toomey, and Chua (1988), this researcher believes:

That the dimensions of low-high-context communication and individualism-

collectivism are isomorphic. All cultures Hall (1976) labels as low-context are

individualistic, given Hofstede's scores, and all of the cultures Hall labels as highcontext are collectivistic in Hofstede's $(1980 ; 1983)$ schema. It, therefore, appears that low- and high-context communication are the predominant forms of communication in individualistic and collectivistic cultures, respectively. (p. 44) 
Gudykunst, Ting-Toomey, and Chua (1988) add that "in developing hypothesis for future research, investigators, therefore, could substitute individualistic for lowcontext and collectivistic for high-context" (p. 57).

Hofstede's work on individualism and collectivism has a business-oriented origin and it was designed to compare cultural values at a national level. Therefore, Hall's theory on $\mathrm{LC} / \mathrm{HC}$ communication is better suited to compare cultural values at an individual level. In the next section the reasons for choosing Hall's work are examined.

Choosing Hall's low-context/high-context approach. When choosing Hall's approach, two attributes stand out: 1) the ability to work with the concept of $\mathrm{LC} / \mathrm{HC}$ on an individual level, and 2) the relationship between communication patterns and cultural behavior.

Although Hall's (1976) theory on low-/high-context systems is based on differences in communication patterns and cultural behavior across nations, he does not advise his reader against $\mathrm{LC} / \mathrm{HC}$ concepts on an individual level. He acknowledges the existence of cultural individuality by stating that there are "differences [within each system] at all levels between people ranging from the interpersonal to the national" ( $\mathrm{p}$. 113). To Hall, differences among individuals are not seen as an error; instead, they are seen as a natural occurrence within large cultural groups. In fact, the cultural difference between a father and a son is the main focus of this study. By observing the occurrence of the slightest cultural shift on an individual level, we may be able to speculate on the cultural future of a nation if enough individuals experience similar shifts. 
In order to compare different cultural values of fathers and sons, we must consider their interpersonal communication as an intercultural encounter (Singer, 2000). Singer has been advocating that every individual must be considered culturally unique once "no person is a part of all and only, the same groups as anyone else and because each person ranks the attitudes, values, and beliefs of the groups to which he or she belongs differently" (p. 28).

Within this conceptual view of intercultural encounters, fathers and sons gain their cultural uniqueness that is of utmost importance to this study, since this uniqueness allows us to contrast and compare cultural values that, in turn, inform communication patterns, that consequently, inform cultural behaviors of each of the participants. In this sense, Hall's (1976) approach of LC/HC systems will provide the necessary framework that will allow us to determine if younger individuals in Brazil are becoming more lowcontext when compared to an older generation.

Several scholars have engaged in individual cultural values studies (Mischel, 1990; Schwartz, 1992; Oishi, 2004; McCrae, 2000) in order to understand how personality is influenced by culture and how this interaction generates certain behaviors in individuals or social groups (McCrae, 2000). An example that blends personality and cultural psychology to contrast individual cultural behavior is the culture versus person versus situation (CuPS) approach (Cohen \& Leung, 2010; 2011). This approach aims at combining cultural shared beliefs (such as honor, face, dignity) to individual viewpoints/behavior in a given situation. 
Cohen and Leung (2011), in a study involving 119 American students that identified with three different cultural values - dignity (Northern Anglo), face (Asian Americans) and honor (Southern Anglos and American Latinos) - have found "that the same 'type' of person who was most helpful, honest, and likely to behave with integrity in one culture was the 'type' of person least likely to do so in another culture” (p. 507). The first part of the study compared students from honor and nonhonor cultures with regard to their belief of endorsing violence and with regard to their actions in two different types of situations: favor versus no favor to repay. Each participant was invited to watch four film clips regarding payback in the "form of honor-related violence" (p. 515). With each participant there were two individuals covertly collaborating with the researcher. One of them offered some pieces of candy to the participant before the movies started and the other did not. The same cooperating individual that offered the candy, also dropped a disk labeled as important at the feet of the participant and at the end of the movies, she or he, left the disk behind giving an opportunity to the participant to return the favor by returning the disk.

The study found, among other findings, that:

Among participants from an honor culture (Southerners and Latinos), those who most endorsed payback in the form of honor-related violence also went the furthest to repay the confederate [cooperating individual] who had given them a gift of candy, compared to those who rejected honor-related violence.... Conversely, among nonhonor groups (Northern Anglos and Asian Americans), 
those who rejected violence expended the most effort to repay, compared with those who endorsed violence. (p. 515)

Thus, individuals from different cultural backgrounds within the same nation with opposing viewpoints on violence-related issues have behaved the same way in a given situation. Similar to the CuPS approach, this present study has the objective of comprehending how individuals internalize, accept or reject the cultural values they are immersed in.

The second reason for choosing Hall's (1976) LC/HC approach is the relationship between communication and cultural behavior. Hall sees communication patterns as a tool to identify low-context/high-context cultural behavior. Dimensions such as direct versus indirect communication style, linear versus spiral logic in thought processes and speaker versus listener-oriented style demonstrate Hall's interest in connecting individuals' cultural values to the way they choose to communicate.

In this study, five dyads of fathers and sons are asked 14 semi-structured openended questions about their experiences with their father-son relationship in conflicting situations. There are two important aspects of language - being the most reliable tool for data gathering - that need to be quickly addressed: the evolving nature of word meaning and verbal thought; and the mutual influence that the social/historical context and language have on one another.

In this thesis, language plays an important role, both theoretically and methodologically. The interviews' transcripts will be analyzed inductively following the recommended steps of grounded theory, which are finding words that represent concepts 
for each phenomenon and gathering similar concepts into categories. These steps will constantly remind this researcher to carefully interpret the meaning of the words each participant chooses to use to express their thoughts.

Vygotsky (1986), in the midst of a theoretical debate about word meaning being a phenomenon of speech or a phenomenon of thought, concludes:

Word meaning is a phenomenon of thought only insofar as thought is embodied in speech, and of speech only insofar as speech is connected with thought and illuminated by it. It is a phenomenon of verbal thought, or meaningful speech-a union of word and thought. (p. 213)

Most importantly, Vygotsky (1986) concluded that although words have a more static characteristic, word meaning and verbal thoughts are dynamic processes influenced by the social-historical-cultural context where the individual is immersed. If the concepts are reached as a result of the constantly evolving social and intellectual experiences of participants, it may be easier to understand what each participant is conveying when we take into consideration his cultural values, and the meanings of his words. Participants may be using the same word to describe a concept. However, the word meaning may vary depending on the cultural context. With data analysis, cultural shifts may be spotted through differences in their thought processes, and therefore, communication patterns. In describing his belief that individual cognition is socially and culturally mediated, Vygotsky (1978) suggests:

Like tool systems, sign systems (language, writing, number systems) are created by societies over the course of human history and change with the form of society 
and the level of its cultural development. Vygotsky believed that the internalization of culturally produced sign systems brings about behavioral transformations and forms the bridge between early and later forms of individual development. Thus, for Vygotsky, in the tradition of Marx and Engels, the mechanism of individual developmental change is rooted in society and culture. (p. 7)

In accordance to Vygotsky's (1978) belief that language and history are mutually influenced by one another, Hall (1976) illustrates this when talking about China, a highcontext culture, which by definition, is deeply rooted in tradition and resistant to changes. Hall explains that if one needs to look up a Chinese word in the dictionary, he or she has to know the significance of 214 radicals. Therefore, contextual information is needed. "For example, to find the word for star one must know that it appears under the sun radical. To be literate in Chinese, one has to be conversant with Chinese history" (p. 91). If individual cognition is mediated by society, one can assume that communication patterns and cultural behavior will vary to some degree if the participants of this study have been exposed to cultural influences that were strong enough to change their understanding of the world. It is only by acknowledging how limited our own cultural framing is that we can step out of our comfort zone to begin understanding how others inform and create their realities. Thus, by grasping other realities and learning from them, we can return to our own world to reinterpret it.

Horizontal theories. Horizontal theories, such as Hofstede's and Hall's, used to compare and contrast cultural values, are openly criticized by scholars, namely Triandis 
(1972), Tayeb (1988; 1994; 2000; 2001), Lowe (2001), Yeh and Laurence (1995),

McSweeney (Hofstede's Model of National Cutlural Differences and their Consequences:

A Triumph of Faith -- A Failure of Analysis, 2002; The Essentials of Scholarship: A

Reply to Geert Hofstede, 2002), Roberts and Boyacigiller (1984), who believe these

theories can be dichotomous, generalized, oversimplified and theoretically insufficient.

As such, these common criticisms will be addressed here, defining the stance of this researcher and the scope of this study.

The two extremes of the LC/individualistic versus HC/collectivistic continuum can easily be interpreted as the only available possibilities to measure the cultural values of a group or an individual. However, most importantly, Hall (1976) and Hofstede (1980) intend to use the continuum as "a conceptual grid in explaining why the meaning of self-conception varies across cultures" (Ting-Toomey, 1999, p. 69) and that "although no culture exists exclusively at one end of the scale, some are high while others are low" (Hall, 1976, p. 91). Along the same lines, Gary Weaver (2000) refutes the dichotomy of such horizontal models by arguing that:

Cultures might be placed along a continuum ranging from the abstractive lowcontext and urban to the associative, high-context and rural. Most cultures tend to fall on one side of the continuum or the other. However, no single culture falls completely within any one category. Differences between cultures are a matter of degree. (p. 74)

With regard to generalization and oversimplification, it must be clear that individuals within a given cultural group or nation will shift along the continuum 
according to the situation, the ways of interacting and with whom they interact. One may choose to use low-context communication at work, when the majority of the information has to be explicit, while at home, one is - naturally — a high-context communicator since the majority of the information needed can be found in the context (Hall, 1976; TingToomey, 1999). Although individuals of the same cultural groups may not occupy the same position, at all times, within the LC/individualistic versus $\mathrm{HC} /$ collectivistic continuum, the fact is that most people from a given cultural group probably behave in a similar manner most of the time (Singer, 2000) and thus are "representative of the culture and consistent with everything else" (Hall, 1976, p. 108) allowing us to understand "how the various "I" identity or "we" identity orientations influence our communication behaviors across cultures" (Ting-Toomey, 1999, p. 69).

Additionally, a group of individuals, such as American women, may be considered more collectivistic than American men. However, when compared to Japanese women, U.S. females will still be fairly individualistic (Ting-Toomey, 1999). Thus, "these contrasts are oversimplifications and generalizations, but they allow us to consider the differences and similarities between cultures" (Weaver, 2000, p. 74).

Finally, to address theoretical insufficiency, Hofstede (1983) argues that researchers must have reliable research methods that are capable of showing, empirically, "that (1) they can be operationalized at the level of nations, that is, related to something measurable or observable and (2) they then appear as, indeed, separate dimensions on which nations can be shown to differ" $(1983$, p. 291). This present study does not aim at analyzing and comparing cross-national cultural values and, therefore, will not attempt to 
fulfill the requirements to address theoretical insufficiency suggested by Hofstede. Using the logic of qualitative inquiry, the interest of this researcher is in comprehending in depth the experiences and perspectives of diverse individuals than being able to generalize those experiences to a large population. This study aims at understanding if shifts in cultural values, at an individual level, are generating conflicts among a small sample of fathers and sons and how the influence of the cultural and social context is affecting their relationship.

Not nearly as severe as cultural misunderstandings can be in a life-threatening situation, they, indeed, can be the reason of problematic interactions in an array of circumstances. Cultural values are deeply ingrained and it is only by developing a strong sense of cultural awareness that individuals can operate adequately in different contextual settings. Stemming from a broader picture of the meaning of $\mathrm{LC} / \mathrm{HC}$ systems, we can then look at the case of Brazil and its aspects of a $\mathrm{HC}$ culture in order to determine if a cultural shift from HC to LC is taking place in the context of the unprecedented exposure of a large number of people to urban and globalized values. 


\section{Chapter 4: Review of the Literature II: Intercultural communication in Brazil The Cordial Man: the Face of a High-Context System}

This chapter focuses on Brazil and it brings together literature pertinent to various disciplines, such as, history, anthropology, Brazilian literature, sociology, and urbanization and globalization theories. First, aspects of Brazil's history that are pertinent to this study are examined in order to highlight some of the elements that contributed to the formation of the Brazilian society. Second, Sérgio Buarque de Holanda's theory of the cordial man, which illustrates qualities of the high-context Brazilian culture, is contextualized and defined. Then, two devices used to mediate conflict within the Brazilian society are presented in order to create a broader picture of the society in which families are immersed. Next, the issue of intrafamilial hierarchy is addressed. The two final sections focus on literature pertinent to urbanization and globalization theories in order to understand if the changes caused by these phenomena have affected the way the younger Brazilian generations perceive themselves and the society they live in, and if they are experiencing a shift from the high-context toward the low-context of the cultural spectrum.

In the same manner that Hall (1976) had an insider perspective on a low-context society and was able to identify issues that could be improved through the assimilation of high-context values, Holanda (1995), through a historical, political, and sociological perspective, examined the national identity of the Brazilian society with critical eyes and suggested remedies associated with values of impersonality and rationality, which are common traits in low-context cultures. In order to understand the concept of the cordial 
man, as developed by Holanda, one must understand the context in which the concept is immersed.

Historical Background. Four works published between 1928 and 1942 have unarguably achieved a status of academic consensus (Morse, 1995; Borges, 1994; Armstrong, 2000; Vainfas, 1999; Rezende, 2008; Cândido, 1998) with regard to the formation of a Brazilian national identity: Retrato do Brasil (Portrait of Brazil) pusblished in 1928 by Paulo Prado (1981); Casa-grande \& Senzala (The Masters and the Slaves) (1933) by Gilberto Freyre; Raízes do Brasil (Roots of Brazil), published in 1936 by Sérgio Buarque de Holanda (1995); and Formação do Brasil Contemporâneo (Formation of Contemporary Brazil), published in 1942 by Caio Prado Junior (1967). Themes such as miscegenation, sexuality, emotionality, culture, slavery and patriarchalism were addressed in order to understand the origin of the social behavior and the composition of the Brazilian society. Moreover, some of these works (Prado, 1981; Holanda, 1995) pointed to characteristics of the Brazilian people, such as luxury and emotionality, which were seen as an impediment to the expected development of the nation. Note that the ideal of "the country of the future," which is present in the Brazilian society to this date, can, in a similar manner, be read in the literature then. In Raizes do Brazil (1995), Holanda, stripped off of any sentimental idealism or patriotism, suggests that the Brazilian people and, thus, its institutions need to be more rational and less emotional, more egalitarian and less discriminatory, if the intention is to develop into a genuine democratic nation based on liberal values. Although the author does not focus nor endorses the concept of the flourishing of the nation — which is the disseminated 
rationale that Brazil has not fully developed into its full potential- -his criticisms relate to this rationale. Holanda (1995) highlights non-functional aspects of the Brazilian society via critical analysis.

A few aspects of the Brazilian colonial history are briefly illustrated to explain how the early stages of Brazil's formation were deeply influenced by an Eurocentric worldview, and thus how it was necessary for the artistic modernist movement in the 1920s and the intellectuals — such as Holanda — in the 1930s to redefine the nation through a purely Brazilian perspective.

The colonial period (from the 1500 s to 1822 ) outlined the economic, political, social and cultural formation of the country's national character. According to Freyre (1933), the colonization of Brazil was unique when compared to other territories in two aspects: the implementation of sesmarias and miscegenation. A third aspect is added in this study to characterize the uniqueness of Brazilian colonization: the migration of the royal family to Brazil in 1808. These three characteristics frame the investigation of country-specific issues, such as nepotism and the importance of personal connections in the public and private sectors, and the delayed formation of a national identity. These issues are key to the understanding of Holanda's (1995) cordial man. Furthermore, these issues are directly related to the thriving of the patriarchal family in Brazil. Patriarchalism guided all levels of interactions, as it came with dynamics of favoritism and particularism, and thus, gave birth to the constant struggle to separate the private from the public interest. 
The policy of sesmarias allowed Portuguese citizens to establish ownership and cultivate large sections of land, and therefore, it transplanted several families from Portugal to Brazil making the new world their new home. According to Prado Jr. (1967), people were chosen based on their financial stability and their connections to the Court or the Portuguese state apparatus. Due to the abundance of land in Brazil and the distance between each property, it was difficult for the Portuguese crown to maintain strict control over landowners' activities. Over the years, preference was given to individuals who could maintain large properties to produce large-scale export commodities, such as sugarcane. The Portuguese occupation strategy contributed to social inequality and originated the formation of latifundia, which remains a problem to this date. Holanda (1995) affirms: "In the rural domain, the land owner authority was never challenged. Everything was done according to his will, and often, in a capricious and despotic manner" (p. 80). Additionally, these vast territories were self-sufficient and were not under the scrutiny of public law. Food, clothing, furniture, religious and general education were available within the property and provided by the patriarchal family. Thus, the need for common individuals to have personal ties to these families was highly important to their survival. Freyre (1933) notes:

The family — not the individual, not even the state or any commercial companyhas been, since the $16^{\text {th }}$ century, the greatest colonization factor; the productive unity; the capital that works the soil, installs the farms, buys slaves, cattle, tools; the social force that transforms itself in politics; the most powerful colonial aristocracy in the Americas. Above the family, the king of Portugal almost reigns 
without truly reigning. The politicians - as an expression of this political familiarity—would soon limit the power of the king, and later [through the independence from Portugal] limit imperialism, or economic parasitism, that has extended its tentacles over the Brazilian colony. (p.19) According to Fausto (2001), measures regarding fiscal policies were attempted in order to establish a clear separation between what was public and of common interest, and what was private and represented the interests of the king and the ruling elite. Rosenn (1995), after analyzing contradictory Brazil-related legal documents from the colonial period, was surprised that the Portuguese "administrative machinery functioned at all" ( $\mathrm{p} 25)$. Rosenn discovered:

The Portuguese did bequeath the Brazilians a canon of statutory interpretation that is but a step removed from the jeito [the action of bending the rules]. The Lei da Boa Razão (Law of Good Sense), enacted on August 18, 1769 ... directed the judiciary to apply Roman law to fill legislative lacunae only when it accorded with "good human sense." ... It encouraged judges and lawyers to look to common sense and the spirit of the law as the basis for decision.... Thus, the Brazilian custom of reinterpreting laws in the light of good sense has enjoyed a respectable and long-standing heritage in Portuguese positive law. (p.25) When referring to the general pattern of relations between the Portuguese state and the colonial neo-Brazilian society, Fausto (2001) claims:

There was a reciprocal movement of the state toward society and society toward the state, which ended up blurring the boundaries between public and private 
space. If on the one hand private interests influenced the state, on the other hand the state's domain was not clearly drawn. Indeed, people (or subjects) had no rights as individuals. The traits of the Portuguese patrimonial state, where everything, after all, belonged to the king, were readjusted to the needs of a colonial society. Family solidarity [meaning personal connections] was more relevant than class interests (p. 33).

Despite racial segregation and extermination, Freyre (1933) affirms that the colonization process in Brazil contrasted the colonial experience in Mexico, Peru or North America since the native population were not only used as a work force, they were also used to establish Portugal ownership of Brazil through family formation, known as cunhadismo or through procreation strategies. Although such miscegenation was, primordially, a product of dominative ideals, the lack of white women and the desire of native women to bear children they believed were of racial superiority contributed to the ethnic enmeshment (Abreu, 1924).

Due to the absence of a socially structured and an economically organized society prior to colonization and the ethnic melting pot that resulted from such process, feelings of racial, social, and intellectual inferiority in comparison to Portugal and later to other societies pervaded Brazil's formation of a national identity for the years to come and, to an extent, still exists today through the ideal of Brazil being the nation of the future. Ribeiro (2000) draws attention to the fact that during the colonization period intellectual knowledge was strongly held by the few who were responsible for the European-based acculturation of others. Additionally, Ribeiro states that the artistic production mirrored 
the aesthetics and what was in vogue in Europe. This necessity to mimic the European lifestyle magnified when the Portuguese royal family moved to Brazil in 1808. Brazil is the only former colonial territory to which the royal family, its court and a large portion of the Portuguese state apparatus, adding up to between 10,000 to 15,000 people (Wilcken, 2004), emigrated.

During the royal family's period of rule in Brazil, personal connections gained significant importance. The neo-Brazilian elite was helpful in welcoming the Portuguese court upon their arrival and provided homes, offices, money and other assets to protégés of Dom João VI. Gomes (2007) reports that, over the thirteen years Dom João stayed in Brazil, he issued more nobility titles than the Portuguese kings had in the last 300 years. In exchange for financial support, Dom João justified the arbitrary distribution of titles and public offices to this elite who was occupied in taking advantage of the situation to enlarge its patrimony. Fausto (2001) states:

The family or the allied families of the ruling class appear as networks formed not just by blood relatives, but by godfathers and godchildren, as well as supporters and friends. As far as the crown was concerned, the state was a royal patrimony, and the governors should be chosen from men loyal to the king. Conversely, the dominant sectors of colonial society tried to break through the state machinery or they tried to curry the governors' favor to benefit the family network. Through different routes, the end result was a government run not according to impersonal criteria based on obedience to the law, but according to loyalty. (p. 33) 
Affective logic and the dynamic of favor permeated Brazil from the beginning of its development and still permeate its society to this day (Rocha, 2004). As the early childhood of adults is important to understand family dynamics later in life, the same connection between the early formation of the Brazilian state and its present dynamics can be made. The affective reasoning, the family ties that trespass the private realm, and the traits of the cordial man criticized by Holanda (1995) result from an ongoing process that rewarded personal connections and status and avoided rationality and impersonality.

The cordial man: origin and definition. In 1932, the Brazilian poet Ribeiro Couto used the expression "cordial man" for the first time in a letter addressed to Alfonso Reyes, a Mexican intellectual and diplomat stationed in Brazil. Couto (1932) characterized the cordial man as a sentimentally available individual who had resulted from the fusion of the Iberian colonizers and the new world with its primitive races. The cordial man was seen as the common denominator that connected the nations of Latin America and distinguished the region from the rest of the world:

(How good it is in the villages of our America, either in my Brazil or your Mexico, when there is a French salesman selling fabric or a German engineer who is studying the local geology, and we invite them for lunch! When they get to our door, we immediately yell: - Kill another chicken!) ... We are people that like to talk, smoke mindfully, listen to the sound of the guitar, sing folkloric songs, invite foreigners for some coffee at our houses and recite poetry to the moon. This sentimental availability is ours; it is Iberian-American. (Couto, 1932, p. 3) 
When Couto was writing the letter, Brazilian intellectuals, artists, and liberal politicians were supportive of a movement to instigate political autonomy and regionalist initiatives to emphasize a national and sub-continental identity. Couto was purposively establishing a separation between "us and them"- Latin America and the rest of the dominant world. When Couto uses the word "cordial" to refer to the behavior of Latin American people, especially Brazilians, he chooses to specifically observe what surfaces in daily human interactions without carefully analyzing what underlies this apparent warmth, sentimentality, sensitivity, and friendliness.

In Raizes do Brasil, which was originally published in 1936, Holanda entitled a chapter the "Cordial Man." Finding the term used by Couto appropriate since it delves into the realm of the Brazilian affective reasoning, Holanda deepens and broadens the concept of the cordial man through the exploration of the social dynamics of the Brazilian society. To him the cordial man was the epitome of the average Brazilian and was seen as an impediment to the development of a truly democratic and liberal nation, which bases itself in values of equality and principals of neutrality and abstraction, instead of particularisms.

Holanda (1995), in line with Weberian rationalization, believed that nepotistic family dynamics, specifically the notion of particularism, inherited from the agrarian patriarchal family, permeated all levels of interactions within the Brazilian culture and, thus, handicapped individuals to develop independent thought and an ethical and impartial mind frame. Note that Max Weber argued that rationalization of a sociopolitical system would detach a society from the personal and emotional ties, 
allowing for impersonal interaction and the rule of law to govern. Richard Morse (1995) notes, "patriarchalism formed an indivisible whole whose members were linked by sentiments and duties... whereas in political theory, Sérgio held, the birth of the state requires suppressing the family order and producing citizens responsible to public law" (p. 54). In conformity with the dichotomous relationship between the patriarchal family_along with its heir, the cordial man — and Weberian rationalization of the political and economical system, Rocha (2004) states:

The patriarchal family sees itself as self-sufficient. The limits of conduct of its members are set by the parameters of the domestic circle. At the same time, a large network of friendships guarantees the expansion of the circle and reiterates its power and its functionality. Stemming from the rural dynamics, this circle only obeys its rules and codes. In short, the patriarchal family is about particular historical contexts, which diverges from the classical models of modernity characterized by the predominance of rationalized and impersonalized relations. (p. 53)

Holanda (1995) agrees with Couto on the existence of an emotional abundance permeating interpersonal relationships in Brazil. However, he explains that cordiality not only encompasses congenial feelings, it also permeates interactions based on disagreeable feelings. The constant need that Brazilians have to operate under the dominance of an emotional mindframe - instead of a rational and objective one-is at the core of Holanda's Weberian-influenced criticism. Thus, cordiality encompasses feelings that are negative as well, since it refers to the personal and impulsive manner people in Brazil 
choose to resolve their issues. In Brazilian Mosaic (Azevedo, 1995), Fernando de Azevedo addresses this impulsive behavior:

Sentiment intervenes constantly in Brazilians' judgments and opinions and reasoning is emotional; they easily believe and spread news of all things strange and miraculous and are not interested in objectivity. All of these factors translate into a tendency to put and resolve everything in personal terms, as "friend" and “enemy." (p. 3)

William Lytle Schurz (1995) concluded that the same emotional intensity that permeated the concept of Brazilian friendship — which was unknown to him and among "the cooler temperaments of northern peoples" (p. 120)—was equally intense when the issue to be solved was based on disagreeable feelings. He observed:

The dominion of affective or emotional considerations complicates the conduct of serious affairs, and makes it hard to settle a question on its merits. It has a marked effect on the functioning of the will, and... people are liable to act on impulse, according to their emotional reflexes. These internal promptings or motivations may be very violent in their intensity, even if short-lived. Thus, crimes are generally passionate actions, committed on the spur of the moment and without plan or premeditation. (p. 121)

Violence is just one characteristic that represents the disagreeable side of the multifaceted cordial man as seen by Holanda. Despite the naïve and stereotypical vision of the Brazilian people found in the works of Freyre (1933), Couto (1932), Louis and Elizabeth Agassiz (1995), Mouralis (1995), and Ricardo (1959), there is some truth that 
"the ordinary, average Brazilians are a wonderful people, cheerful, sweet-tempered, witty, and patient” (Bishop, 1995, p. 129). In agreeable situations or in situations where honor-related issues are not at stake, Brazilians tend to smooth things over and speak in an indirect manner in order to respect hierarchy and maintain social relations intact (Rocha, 2004). However, it is sociologically inefficient to believe that Brazilians lack complexity in their character formation. The cordial man's emotions as described by Holanda, the difficulty to resolve conflicts objectively, and the deeply rooted honor culture contribute to episodes of emotional distress and even violence, which is a force embedded in Brazilian society.

Rocha (2004), in response to those who insist in mistakenly seeing an incompatibility between cordiality and violence, states:

There is no contradiction with regard to the violence of the cordial man. Depending on the situation he can be very violent as he can be exaggeratedly agreeable, very loving and extremely rancorous. At times he can experience opposite feelings simultaneously, but always with great intensity. There is a perfect Spanish expression to describe the cordial man: vivir de corazonada or living as the heart commands. The reasoning of the heart follows a particular logic: the affective logic, which defines the private realm. How to conciliate the way of being of the cordial man and the European-standard public sphere seen as an impersonal dominion where every citizen must possess the same rights and duties? (p. 36) 
In a study conducted in the Brazilian states of Distrito Federal and Bahia by the Sarah Kubitschek Hospital, out of 1,578 hospital admissions in 1999, 345 patients, or 20.6\%, were non-fatal victims of firearm-related injuries (Rede Sarah de Hospitais de Reabilitação, 2012). Most of these cases were the result of intentional shooting. Looking further into the details, $32.3 \%$ of the perpetrators were known to the victimsacquaintances, friends or family - and in $25.5 \%$ of the cases the shootings were a result of non-criminal interpersonal disputes, such as fights and discussions. Recognizing that these results cannot be generalized to the entire Brazilian population and correlation does not mean causation, these numbers nevertheless show that easy accessibility of firearms to emotionally unbalanced people can be lethal. The National Report on Firearm-related Violence in Brazil (Peres, 2004) concludes:

These data are consistent with, and support, an evolving awareness within Brazil that patterns of violence have changed in the country. Interpersonal disputes such as quarrels among neighbors, between families and in traffic disputes, all of which would most often be banal, increasingly culminate in grave injuries and death when the dispute escalates to involve a shooting, facilitated by the presence of a firearm. (p. 20)

The intention in presenting this data is to emphasize the lack of criticism when individuals choose to ignore the existing social inequality and violence, and see the Brazilian society as a "social oasis, indifferent to conflicts and revolutions" (Rocha, p. 65). 
The romantic idealism that inhabits the Brazilian imagination is not limited to a particular social class. Rezende (2008) examined how Brazilian scholars, who have studied in Europe and the United States, related to the stereotype that sees Brazilians as warm, easy to make friends and very open people. He interviewed twelve middle class academics with regard to how they experienced the Brazilian emotionality when they were developing new friendships abroad. Results showed that subjects embraced these stereotypes and believed they were positive traits of the Brazilian national identity. Making local friends seemed to be the "most significant index of social adjustment" (p. 117) and most academics had difficulty in making local friends, and thus, felt excluded. The difficulties most subjects found in making friends were attributed to the unapproachable behavior of locals, while Brazilians were perceived as superior due to their openness and willingness to make friends.

It is a mistake to believe that Brazilians do not distinguish between insiders and outsiders. Similar to every high-context culture, Brazilians have a strong sense of community values, but they live in a society where laws that characterize the public sphere are inefficient and are overruled by personal connections. Thus it is pivotal to befriend as many people as they can to guarantee their survival. This can be confusing to foreigners who experience this "Brazilianess." They see Brazilians calling strangers "friends" and functioning in a seemingly cooperative environment. As a member of this large personal network, Holanda argues:

[To the] cordial man, social life is to some extent true liberation from the panic that he feels from living with himself and from depending on himself under all 
circumstances of life. His way of revealing himself to others continually reduces the individual to the social and peripheral part of life, which in the Brazilian — as in a good American - tends to be what matters most. Above all he lives through others. Nietzsche addressed this type of human being when he said: "Your inadequate love of yourselves turns isolation into captivity.” (1995, p.147) This apparent cordiality is confusing not only to foreigners, but Brazilians have also constantly misunderstood this antihero as portrayed by Holanda. Cassiano Ricardo, a Brazilian journalist and poet, wrote that he was confused by Holanda's definition of the word cordial, since "[Holanda] defines the cordial man as the contrary of polite, while, among us, cordial exactly means being polite" (Ricardo, 1959, p. 11). Ricardo is unique from other misled authors since he was the only one that received a "cordial" response from Holanda included in the second edition of his book.

Richard Morse illustrates the inclination for misinterpretation, as well, when he states, "Sérgio's often misunderstood "cordial man" is not an amiable patrão [patron] who oils the gears of oppression in the interest of "peaceful" accommodation" (Morse, 1995, p. 148). Elvia Bezerra complements by saying “after so many years and so many explanations [given by Holanda and others], many people insist in seeing the "cordial man" through the eyes of Ribeiro Couto" (Bezerra, 2004, p. 130).

Several traits of the Brazilian character exposed by Holanda are in accordance with Hall's classification of high-context societies. The fear of distances that impersonality creates, the need to feel included, the concept of emotionality, the lack of objectivity and exactness, the indirect communication that keeps social interactions 
undisturbed and the awareness that Brazilians have regarding the silent rules of their society are themes explored in Holanda's work and represent what Hall perceived as group-oriented values, spiral logic, indirect style, status-oriented status and context-based understanding.

Holanda (1995) speculated that a power shift from a centralized patriarchal family to a decentralized institutional structure would weaken the roots of the cordial man, and that within the rational urban nest, relationships based on impersonality and equality would overpower personal connections and favoritism. In the upcoming subsection, this study focuses on the devices used by the cordial man to navigate Brazilian society and mediate conflict, and questions whether or not the cordial man has been able to confirm his supremacy in an urban and globalized world.

Devices used to navigate through society and mediate conflict. This section describes the tools used within the Brazilian society to navigate the social and legal system when a situation is difficult or forbidding.

Brazil, as a high-context system, has been traditionally characterized by its high power distance and status-oriented style. In such societies, individuals have a higher tolerance for unequal distribution of power and, thus, must develop behaviors to help them navigate within this disproportionate system. Each HC society manages power distribution differently. For instance, Holanda (1995) compares the Brazilian cordiality to the Japanese politeness and formality, which are different ways to manage high power distance, and concludes: "No people are further from that ritualistic notion of life than the Brazilian. Our usual form of social relations is basically just the opposite of politeness. 
It can be deceiving" (p. 147). The reasons to explain the differences in dealing with hierarchy between these two high-context countries are varied, ranging from historical background and religious orientation to gender issues and economic development. Although this is not a comparative study between Japan and Brazil, there are two differences that help to explain why Brazilians reject distances and formalities.

First, Brazilians live in a society where corruption is widely accepted. This is not to say that Japan, or any other country, do not experience political or systematical corruption. In Brazil, though, the acceptance of corruption-including the bending of rules or acting immorally or illegally - is not the exception; instead, it is almost the norm. This acceptance of corrupted behavior is directly related to the unequal distribution of power, or social status, that permeates the Brazilian society. Individuals do not confront the powerful party directly — unless a matter of honor is at stake-nor they will resign to their fate; Brazilian people would most likely find a way to achieve what is desired without disrupting the status quo. Thus, despite the generalized discontent expressed by the population with the reoccurring political corruption in the Brazilian public arena, people in their daily transactions may act in corrupt ways.

Silvia Cervellini (2006), of the Brazilian marketing research company IBOPE Inteligência, surveyed a sample of 2,001 individuals that represented the Brazilian national electoral poll. Participants were asked about illegal activities in their daily lives - from bribing a police officer to avoid a parking ticket to using fake documents to take advantage of something - and about their tolerance for corruption performed by their elected politicians. The results showed that $98 \%$ of the subjects knew people who had 
engaged in illegal actions and 69\% admitted to acting illegally themselves. Additionally, $75 \%$ of the subjects believe that, if they were these politicians under the same conditions, they would also be inclined to performing the same actions of corruption.

Such high numbers support Holanda's view that the Brazilian politeness can be deceiving when compared to the Japanese society, and this is due to the existing gap between the reality of the Brazilian social practice and the ideal and artificial norm (Barbosa, 1992). Politeness can only be sincere if polite actions reflect the person's own feelings and thoughts about these actions. If a person does not believe that waiting in a queue is beneficial to the society overall, why would he or she dismiss the opportunity to cut in line when he sees an acquaintance with whom he can be cordial to accomplish what he wants? The same can be said about Brazilian laws, which appear to be an unwanted wall preventing people from living according to their level of appreciation for the common good: if the disabled parking spot is free, why should I not try to climb this unwanted wall just for ten minutes? Guerreiro Ramos, according to Livia Barbosa (1992), finds the root of this behavior in what he calls formalism, which is defined as "the existing discrepancy between our social, political and juridical institutions and our social practices" (p. 12). Ramos believes that "formalism is a global strategy of such societies [Latin-American countries] to overcome the social development phase in which they find themselves" (p.12). The second difference between two high-context countries, such as Brazil and Japan, regarding ways to manage power distance is related to the distinct concepts of honor and face. 
Cohen and Leung (2011) discussed how societies of both groups behave regarding their social order and the problem of valuation. In both cultures, there is a preoccupation with others' perceptions of self and claim to virtue and prestige is common. However, the settings and the expectations are different in both cultures. In cultures of honor, such as Brazil, individuals cannot depend on the state to protect and be fair to them since the state fails to treat its citizens with equality. Therefore, people are not automatically trusting and, as a consequence, hierarchical organization suffers from a state of uncertainty. Hierarchy will not be fully respected - to your face or behind your back - until there is a trusting relationship between the parties involved. Before that, individuals from an honor culture will protect themselves by seeing others as competitors. In honor cultures, an individual may claim to have honor, but he or she only truly has it if others perceive him as such. "In the absence of state protection, selfprotection through violence or the credible threat of violence is necessary: a reputation for toughness deters competitors who would enhance their own honor or claim to precedence by taking some of yours" (p. 510).

In face cultures, Cohen and Leung (2011) explain that hierarchy is settled, as individuals do not need to protect themselves as much as individuals in honor cultures. All people have face until they lose it, and one individual cannot take face away from another since this would not be a behavior that caused admiration of others. People are respected and have prestige based on their hierarchical positioning, and cooperation, instead of competition, is sought. According to Cohen and Leung: 
If one person openly aggrieves another, it disrupts the harmony and order of the system. And unlike in honor cultures, it is not incumbent on the victim to directly redress the grievance him- or herself. Direct retaliation by the victim is unnecessary because the group or a superior is able to punish the offender; in fact, direct retaliation would be undesirable because it would further upset the harmony of the system. (p. 510)

Thus, in face-culture Japan, formality and politeness are common behaviors to display when interacting with others, especially if the interacting parties belong to different hierarchical positions. Additionally, the level of civility of the Japanese society has allowed individuals to live according to the laws established in the public arena.

In Brazil, the relationship in terms of power distance is ambiguous. Although status - which is prone to change with the fluctuation of wealth and prestige — defines one's positioning within the Brazilian society and trust-based hierarchy, mainly in the professional and familial realm, is respected, Brazilians do not appreciate the impediments that such power distance brings to their daily lives. When a Brazilian individual does not obtain what he perceives as necessary, he does not accept a negative answer easily. This cordial man may resort to creating an emotional connection with the party that is denying him — such as by trying to befriend the person, finding a common background they share, explaining difficult personal aspects of his life. He may even resort to finding a way to bend the rules or finding a crack within the law that will allow him to achieve what he desires; if necessary, he would be willing to use bribes. He will always try to find a way: um jeito. If nothing works, the cordial man would try to boast 
about this hierarchical positioning within society and use the infamous Brazilian sentence: "você sabe com quem está falando? (Do you know with whom you are talking to?)

Rocha (2004) affirms that Holanda's cordiality should not be seen as a trait unique to Brazilians, since such mannerism could blossom in any society where private interests dominate the public sphere. Although such behaviors exist in every society, they are often regarded as the exception. In Brazil, however, they are almost the rule. Most — if not all—Brazilians are able to describe what jeito means. This cultural aspect has been noticed by foreigners (Kellemen, 1995; Santos, 1995; Moog, 1995; Glenn, 2009) and studied by Brazilians, being the works of Roberto DaMatta (1991; 1994; 2004) and Lívia Barbosa (1992) the most relevant guides in this matter.

Jeito. Lívia Barbosa (1992) researched the Brazilian jeitinho for her doctorate dissertation in 1986. After surveying and interviewing 200 people from various cities, professions, ages and backgrounds, she noted that all participants were familiar with the jeitinho and not much definition variation was found:

To everyone, in general terms, the jeitinho is a special way to resolve a problem or a difficult or forbidden situation; or it is a creative solution to some emergency. This creative solution may be in the form of breaking some rule or pre-established norm, or in the form of conciliation, or by being cunning or skillful. Therefore, for a situation to be considered jeito there needs to be an unforeseen and adverse circumstance that goes against the objectives of the individual. In order to resolve the problem, a special—efficient and fast—resolution is needed. Not any strategy 
will work. The one to be adopted needs to produce short-term results.... It does not matter if the chosen solution is definite or not, ideal or provisory, legal or illegal. (p. 32)

Besides being a detailed and specific description, this definition also identifies the existing ambiguity involving the jeito. On the one hand, the jeito pushes individuals, against all odds, to pursue what they perceive as necessary. On the other hand, it represents the belief that the end justifies the means and that rules are not equally applied to everyone.

The Brazilian engineer Ramon de Paula sees the jeito as a positive trait. As a NASA employee, he manages projects that, at times, involve more than 500 people under his supervision. His specialty is solving bureaucratic and technical problems in all sorts of missions. In an interview given to BBC Brazil (Puff, 2012), the engineer claims that the Brazilian jeitinho was vital to his career. Paula states:

The fact that I am Brazilian has definitely helped. My job requires me to find solutions to mission-related problems, and everything that I have learned in Brazil, allied to our culture were decisive factors. My mantra here is: there is always a jeito to solve the problem. Not every culture has that flexibility in the face of challenges.

A diligent professional trying to think outside the box to solve problems of his work environment — without any harm to others — is different from a person who tries to use the jeito to his own advantage. Thus, diligence is dissimilar to jeito due to the latter's connection to personal gain. However, there is a common denominator between 
diligence and jeito in Brazil—which could be the reason for the confusion between both terms - and that is the aversion that Brazilians have to the word "no." In high-context societies, the way people deliver messages must be carefully considered. In Brazil, messages are delivered indirectly_almost in a shy fashion, as Rocha (2004) observedin order to keep social relations undisturbed. The difficulty found by the cordial man to say "no" to people in his private circle is the same that he experiences when people say "no" to him in the public arena.

Barbosa (1992) has also differentiated the jeito from other similar categories such as favor and corruption. The three categories are placed in a positive-negative continuum in order to illustrate the participant's views of each one. Favor is at the positive end of the continuum; corruption is at the negative end, while jeito is right in the middle.

Favor is identified as a situation where direct reciprocity is present and a hierarchical relationship between the provider and the receiver is established. Additionally, favors are usually asked to family and friends. To ask someone to give a jeito does not imply that a direct reciprocal relationship is being established. The reciprocity, in this case, is indirect, since the individual who was granted the jeito willmost likely_-be in a situation in the future where he will have the opportunity to give a jeito in someone else's case. Moreover, the jeito differs from favor once it usually involves the bending of some rule and it can be asked to strangers.

Regarding jeito and corruption, Barbosa (1992) argued that the difference resides in the amount of money involved in the transaction: small sums of money or small compensations — such as beer or coffee-is classified as jeito; larger amounts of money 
or valuable compensation would characterize corruption. The differences between these three categories became more precise as the level of education of participants increased. Additionally, if the participant saw the jeito as a positive trait, he saw a relevant difference when Barbosa compared it to corruption. If the participant considered the jeito a negative tool, he found the two categories to be similar.

Although similar navigational tools are present in several cultures - such as in Germany, Italy, India, Egypt and Russia (Duarte, 2006)—Barbosa (1992) claims that no other culture uses the jeito, once there needs to be a social recognition and acceptance of such mechanism. "In Brazil, the jeitinho not only characterizes a specific situation but it is also an element of social identity" (p. 16).

Roberto DaMatta (2004) explains that the constant need to bend the rules - the jeito - is the result of disequilibrium between the person versus the individual. The person is represented by one's private life, while the individual is represented by one's public life. The dichotomy created by the author is symbolically portrayed by the conflict between two different social units: the home and the street. The author connects the home to the heart, since within this social unit the rules are created based on emotional ties. At home, there is a set hierarchy, thus, there are no rules that must be followed by everyone equally. However, the street is impersonal. Rules are there to be followed by every individual, thus the need for the jeito.

Você sabe com quem está falando? This well known expression translates from Portuguese to "do you know who you are talking to?" and is used with the intention of establishing a hierarchical differentiation between interacting parties. In such interaction, 
the individual using this formula is focused on achieving a goal but finds a personified impediment. DaMatta $(1991,2004)$ has studied the subject in depth and explains that this formula may be used when the jeito has failed to work. Você sabe com quem está falando? can be seen as "an explosion of the jeito" once affective reasoning and emotional ties succumb to authoritative and hierarchical logic. The difference between the two navigational tools can be seen in the following anecdotal situation:

The laws regarding driving under the influence have been recently modified and have become stricter. The message sent by the government is that such laws must be applied to everyone equally. Throughout the carnival holiday of 2013 several incidents regarding this theme were reported by the media. A young man, who claimed to have had only one beer, asked a police officer if he would make an exception and finally asked for a jeitinho while offering the officer some cash. A woman was also stopped by a police officer. She was clearly drunk. As the police officer questioned her, and proceeded with the legal paperwork, she quickly appealed to her social status within society: "do you know who you are talking to? I am a judge. I could get you fired!" Você sabe com quem está falando? is a practical representation of what Hall theorized as status-oriented communication style. Although such tool is unlikely to be used within familial dynamics, it is relevant to be addressed once family and society are mutually influenced and it shows the importance given to social hierarchy within the Brazilian society.

Intrafamilial hierarchy. The family is one of the most highly regarded social units in Brazil. Historically, Brazilian families were characterized by having a diverse 
number of individuals as a part of it: parents, children, grandparents, sons, daughters, aunts, uncles, nieces, nephews, in-laws, religion-related members, servants and close friends. The patriarchal family model met the needs of a rural society in which large plantation properties functioned similarly to feuds. Besides being formed by large extended families, the patriarchal family model was characterized by set hierarchies in which the father represented the highest authority within the family (Freyre, 1933; Holanda, 1995).

Although families in Brazil are experiencing changes brought by modern challenges, the patriarchal family model is still regarded as a reference (Machado, 2001). In a masculine society, such as Brazil, the legacy of the patriarchal figure still contributes to the dynamics of families. DaMatta (2004) portrays the Brazilian family in a vertical manner, in which men are placed on the higher end of the hierarchical line, followed by children, and at last, by women.

Hierarchical authority in Brazil is present in three distinct arenas that are mutually influential: the social, the familiar and the religious. Although Brazilians will try to find ways to overcome the difficulties brought by hierarchical differences, the social environment is permeated by such differences. The navigational tool—você sabe com quem está falando? - is an example of the inclination that Brazilians have in placing themselves in a hierarchical order.

According to the 2010 Brazilian statistical bureau (IBGE), nearly $87 \%$ of the population is Catholic. Catholicism exerts a strong influence in the lives of citizens and it is responsible for shaping values that are absorbed by families. Hierarchy is an important 
concept within the Catholic religion, which is illustrated by the several levels between humankind and God. In a society in which social and religious values abide to hierarchical positioning, it is only natural that families will have the tendency of structuring themselves hierarchically as well.

\section{Urbanization and U.S.-Influenced Cultural Globalization}

Theories of urbanization and cultural globalization in Brazil are analyzed to understand if the changes caused by these phenomena have affected the way the younger Brazilian generations perceive themselves and the society they live in, and if they are experiencing a shift from the high-context toward the low-context of the cultural spectrum.

Urbanization in Brazil after 1970 and the future of the cordial man. By 1970 more than fifty percent of the Brazilian population had emigrated from rural areas to urbanized centers (Wagner \& Ward, 1980). In 2010, according to the Brazilian census bureau, out of around nearly 191 million inhabitants, 161 million lived in urban areas and 30 million lived in rural areas (IBGE, 2010).

Despite the massive regional transition and the consequential decline of the rural patriarchal family, the cordial man, in opposition to what Holanda had predicted, has been able to find shelter within an industrialized society (Barbosa, 1992; Rocha, 2004). "While constituting his codes and imposing his gestures, the cordial man created conditions to 'survive' in the urban universe, due to his indiscrete attachment to the power structures generated in the bosom of the patriarchal family." (Rocha, 2004, p. 300) 
Within the public realm, a solid network of favoritism, in which the cordial man was able to successfully function, replaced the rural and dominant patriarchal family model. Families were also transformed by industrialization and urbanization. Their migration from a familiar and rural context to an urban reality changed their network of support. Instead of counting on a large extended family, the cordial man had his wife and children as his most trusted support web, followed by the individuals he had to befriend to guarantee his survival in the city.

In an article regarding the interdependence between family and society, Dias (2000) confirms that the industrial and urban processes influenced the decline of the large patriarchal family and supported the rise of the small nuclear family. In an urban environment, the child mortality rate decreased and life expectancy increased, therefore, families could afford to become smaller. Although the exile of the cordial man from the rural to the urban arena has been addressed, there are no studies about his relationship to his family living in a globalized society.

\section{U.S.-influenced cultural globalization in Brazil after 1990 and the future of}

the cordial man. With the end of the Cold War in 1989, the international bipolar system came to an end. A new unipolar scenario - if U.S. military and strategic supremacy is considered — or a multipolar scenario - if the economic and influential power of some European and Asian countries is considered-emerged in the 1990s. This new scenario based itself on neoliberal ideas and the free market; and it functioned as an arena to the vertical and horizontal expansion of globalization. Post-Cold War globalization did not present itself as an alternative; instead it became the only and irreversible way for 
countries to follow in order to maintain themselves connected to the international system. Rodrigues (1994) argues that economic globalization proceeded in the context of a competitive system, such that countries in debt did not have the power to protect their industries and, therefore, were left with little leverage for bargaining.

In Brazil, mostly during the administration of President Fernando Henrique Cardoso (1995-2002), there were two paradigm shifts that consequently influenced its foreign relations. The first was related to the consolidation of democracy, which was a process that had started in the 1980s but was still underdeveloped in the eyes of the international opinion. The Cardoso administration worked diligently to adjust the diplomatic discourse to the goals that had been internally established to promote democratic values and practices. The second paradigm was achieving a greater awareness of international markets and more openness in order to become a global trader (Cardoso in Lampreia, 1999, p. 10).

Throughout the eight years of the Cardoso administration, the United States was Brazil's closest political partner. Although both nations had been trade partners since the 1920s, their relationship has strengthened once it became evident that Brazil was shifting toward democracy, embracing globalization, and adopting similar American values. The United States during the Clinton administration was also interested in finding a partner to share the onus of leadership in South America. Several bilateral projects were developed in order to build on this renewed partnership, including the cooperation agreement in the educational field, which was responsible for the exchange of hundreds of professors 
between both countries. Additionally, the following factors also helped to strengthen the relationship between Brazil and the United States:

The decrease of deforestation in the Amazon, the increase of American direct investments in Brazil, the good news regarding the economic stability brought by the Brazilian monetary plan, the increase of American goods in the Brazilian market generating a surplus in the American balance of payments and the increase in the touristic flow between both countries. (Silva, 2002, p. 308) Looking at globalization through a cultural standpoint, we need a comprehensive definition of the phenomenon.

First, globalization consists primarily of two major directional tendencies, increasing global connectivity and increasing global consciousness.

Consciousness does not imply consensus, merely a shared sense of the world as a whole. Second, globalization (...) is focused upon four points of reference: nation-states; world politics; individuals; and humankind. Third, globalization is constituted by four major facets of human life-namely, the cultural, the social, the political and the economic. These dimensions are in reality heavily intertwined, one or two aspects being more prominent at any given time or place. For example, in the modern world the cultural and the economic are closely interpenetrative. (Robertson \& White, 2007, p. 64)

Cultural globalization, therefore, is the increase of global connectivity and consciousness that individuals experience regarding customs, arts, social institutions, traditions, beliefs, values, norms, meanings and achievements. Without historical 
precedents, the advent of cultural globalization has minimized the boundaries between states and cultural groups. The Internet, communications media, and the increased accessibility to international traveling have lead to a greater exposition of different cultural values and traditions to a larger number of people.

Tomlinson (2007) claims that cultural globalization should not be seen as a consequence of the interconnectivity of the international markets. Instead, it should be comprehended as a reflexive process in which culture also influences the preferences of the market, thus affecting the global economy. Although it is true that cultural fads contribute to production and market demand, it is the forces of the market - through marketing research or consumerist propaganda - that majorly influences the desires of clients. By stating that economic and cultural globalization are mirrors of one another, Tomlinson (2007) removes corporate responsibility and minimizes the power and impact global enterprises have on people's lives. Both dimensions of globalization have different roles and influential power.

Throughout history, dominant civilizations have served as reference for weaker or less developed cultural groups. Since the First World War, the United States has been a prominent actor in the global arena. U.S. traditions, values and products have been exported to several countries in the world through the dissemination of movies, music, books, food, clothing and other goods. The sociologist George Ritzer (1998) analyzes the impact that U.S. fast food restaurants and credit cards have on foreign cultures by stating:

The fast food restaurants are bringing to the rest of the world not only Big Macs and French fries, but more importantly the American style of eating on the run. 
The fast-food restaurant brings with it the idea (and the structure to implement it) that eating is something to be completed as quickly and effortlessly as possible. Similarly, credit cards make it easier to purchase American goods.... Fast food restaurants and credit cards are beginning to flood the globe, and to bring with them the Americanization of local cultures. (p. 84)

With the advent of globalization, "Americanization" was intensified once individuals became more connected and more aware of the American way of living. Additionally, the expansion of U.S. enterprises to developing countries and the increase of multinational companies of U.S. origin have generated employment opportunities to thousands of people, thus directly exposing workers to low-context corporate practices. The local financial newspaper Valor Economico reports that the four most powerful enterprises in Brazil—Google, Apple, Microsoft and Facebook—are of U.S. origin and are considered to exert strong influence on the lives of consumers (Malta, 2012).

In a qualitative study regarding the corporate culture in Brazil pre- and postglobalization, Chu and Wood (2008) interviewed 16 Brazilians and 9 foreigners with managerial experience. Results showed that the corporate culture is permeated by three main characteristics: transitory character, hybridized identity, and reassignment of values and practices. Their study showed that the corporate environment continues to be unpredictable and unstable since it lacks organization, structure and planning. Relationships are based on power distance, authority, personal connections and conflict avoidance, which are practices that tend to focus on people more than results. Furthermore, foreign references are still assimilated in an uncritical manner. On the other 
hand, changes are happening due to economic globalization and the internationalization of businesses. The rise of multinationals and the adoption of foreign corporative practices are changing managers, who are becoming more cosmopolitan, modern and open-minded, as they adopt standardized and systematized managerial practices with focus on results and performance.

The characteristics presented in the study above illustrate how globalization is affecting the professional practices and cultural values of the professionals interviewed. The corporate environment is in a transitional phase where old habits - such as the jeito and the need to maintain personal relations undisturbed in order to be productive - are being challenged by low-context practices. Both HC and LC systems, after 20 years of globalized practices, still coexist and struggle to adapt to one another. Thus, if Brazilians are being exposed to American low-context values through various mediums-at work, at the cinema, when reading, when watching American TV series, when listening to music, when eating, when browsing the internet—how are these expositions affecting families, specifically fathers and sons who identify with different context systems?

\section{Research Questions}

The literature review and the findings of this study created the theoretical framework to investigate to the following research questions. First, is Brazil's younger generation-born after massive urbanization in the early 1970s and influenced by the U.S. cultural globalization in the $1990 \mathrm{~s}$ - experiencing a shift within the LC/HC spectrum? Second, does this shift affect intrafamilial relationships between generations 
that identify with different systems? Finally, who is the cordial man and can he adapt to a world that is becoming more dissimilar to his rural and patriarchal native habitat? 


\section{Chapter 5: Methodology}

Building on a literature review of academic research on high- and low-context systems, the roots of the cordial man, urbanization, and cultural globalization, this is a qualitative study that employs grounded theory as its strategy of inquiry. In this chapter, reasons for choosing grounded theory as the strategy of inquiry are addressed. Then, the design of the study - including sample access and selection, setting, protection and procedures - is explained. The following section examines the ethical concerns related to this study. After that, the methods utilized in this study to address the validity threats are examined, and are followed by the perspective of this researcher on the generalizability and representativeness of the present study. Finally, the steps that guide the data analysis process are examined.

\section{Choosing Grounded Theory}

Grounded theory, among other strategies of inquiry within the qualitative approach, was selected to frame this research due to its flexibility and ability to generate theory according to findings from data. Flexibility and possibility of working with an evolving theory are two important methodological aspects to consider in this research, since the topic is relatively unexplored. The book, Basics of Qualitative Research: Grounded Theory Procedures and Techniques (Strauss \& Corbin, 1990), has been chosen by the researcher as a reliable guide to develop an empirically strong and trustworthy research mechanism. Strauss and Corbin (1990) claim that "a well-constructed grounded-theory will meet four central criteria for judging the applicability of theory to a phenomenon: fit, understanding, generality, and control [bold by author]" (p.23). 
A theory is fit when it is carefully derived from data that precisely represent the routine of the area or phenomenon being studied (Strauss \& Corbin, 1990, p. 23). When applying the fit criteria to this study, it is logical to assume that a credible theory will only emerge if the data gathered from participants are as close to their realities as possible. Thus, what is felt and perceived by each participant allows for an intellectual explanation, a theory, of his experiences. In terms of theory, understanding is when participants and conductors of a study grasp the same meaning in the same fashion (Strauss \& Corbin, 1990, p. 23). As mentioned in chapter 2, member checking is applied in this research to guarantee that the theory emerging from the data and from the perceptions of the researcher is also in compliance with the viewpoints of the participants.

A theory is general when "the data upon which it is based are comprehensive and the interpretations conceptual and broad, then the theory should be abstract enough and include sufficient variation to make it applicable to a variety of contexts related to the phenomenon" (Strauss \& Corbin, 1990, p. 23).

The final criterion to develop a reliable grounded theory according to Strauss and Corbin (1990, p. 23) is control. Even though the theory should be broad enough to explain diverse variables related to the same phenomenon, it should be specific enough with regard to taking action towards each variable of the phenomenon studied. There is a need to carefully outline the procedures and actions to be taken according to each specific situation - in other words, a need to deviate from the generality of the theory.

\section{The Design of the Study}


Sample access and sample selection. I used two types of sampling strategies to select ten to twelve subjects to participate in this study: snowball and criterion sampling. First, I sent an e-mail to people with whom I have a direct relationship, which could be of a professional nature or family or friends, and I asked them to forward the e-mail to people they know (snowball sampling). This e-mail (see Appendix A) briefly explained the purpose of my research, the general issues to be addressed during the interview, anonymity, length of interview, location of interview, and it informed participants that they could decide on what they wished to talk about and that they could stop the interview at any time. The e-mail also contained three criteria for participating in the study (criterion sampling): (a) subjects must be father and son; (b) sons must be 18 or older and be born in a large and urbanized city; and, (c) fathers must be born in small or rural towns.

Setting. The participants in this study were asked to choose a place where they felt most comfortable being interviewed. The researcher made transportation available to the participants. If participants chose to be interviewed in a public place, they were warned about the risks regarding confidentiality and were asked to sign an informed consent stating they were notified of the risks and chose to proceed with the interview. If participants expressed the wish of meeting in their own homes, the researcher asked the participant to choose a quiet time and place. Participants were asked to turn off their phones and avoid, when possible, interruptions of all sorts. Since participants might discuss their feelings and opinions about intrafamilial conflict, the researcher strongly advised participants to meet in a safe and private space. 
Protection. The interviews were recorded in three ways: (a) on a minidisc player; (b) on field notes handwritten in a notebook at the time of the interview; and, (c) on field notes that were expanded in computer files after the in-person interview. All subjects remain anonymous in the thesis manuscript. I use pseudonyms to conceal identities, which participants created if they wished. All links between pseudonyms and real names are kept separately. There were no group interviews or focus groups. I am the only person with access to the research data, minimizing concerns about the identity of the subjects being disclosed. It was noted in the introductory script and in the consent form that I would be recording the interviews. All materials related to this thesis (interviews, recordings and notes) will be stored in a locked file cabinet in my home for the duration of three years after the research is completed. The digital files on the computer are safeguarded by login and password only known to myself.

Procedures. Subjects were asked to individually participate in an in-depth interview with the researcher lasting no more than two hours. The purpose of the interview was to explore their experiences with their father-son relationship in conflicting situations. There were 14 semi-structured open-ended questions asked in a certain order. Questions addressed the following themes: perception of self, upbringing, decisionmaking process within family, father-son relationship, communication, ways to influence and be influenced, history of conflict and urbanization and globalization. Participants' responses — guided by their value system — were helpful in revealing how group-oriented or individualistic these values were and if the cordial man behavior was also present in 
the intimacy of their homes. Participants were informed that if any question made them feel uncomfortable, they could skip it and move on to the next question.

In a study regarding solidarity and conflict in intergenerational households, the researcher concluded that using semi-structured questions to interview family members was helpful for two reasons. First, they "provided an opportunity to collect data on their shared as well as their differing perspectives" and, second, "they were suited for situations in which the researcher meets the respondent only once" (Lowenstein, 2002, p. 227). Since this researcher also interviewed two generations from each family and met each participant only once, semi-structured questions were a good fit for this study.

The interviews were recorded in Portuguese and later transcribed verbatim directly to English. However, participants could request an off-the-record conversation. If there is something they told the researcher off the record of particular significance, the researcher asked their permission to use it in general terms so they would not be personally identified. Before submitting the final research to Portland State University, the researcher contacted participants to share the findings and confirmed that their statements and viewpoints were unchanged and consistent.

Before each individually conducted interview, an informed consent form was presented to the potential participant. It clearly explained the purpose of the research, the potential risks and benefits to the subject and the expected use of the data gathered. Each participant was informed that his identity would be protected by a pseudonym, which could be created by him or by the researcher. Fathers and sons met the researcher individually and were informed that they would remain anonymous to everyone, 
including each other. Participants had the option of withdrawing from the study at any time without any penalty.

\section{Ethical Concerns}

Any information that is obtained in connection with this study and that can be linked to participants or identify them will be kept confidential. All comments, which could identify participants to their son or father, were obscured or omitted. Participation in this study is also being kept confidential to everyone, including the mutual acquaintances who identified individuals as potential participants for this study. If there was something of particular significance that could identify participants, the researcher came back to them and specifically asked for permission to include the material in the study.

None of the information the researcher gathered from the interview will be released to any other person or agency and will be used for the sole purpose of this study. Except for the data used in the thesis, all other transcripts and recordings from the interview are stored in a locked filing cabinet and will be kept confidential.

\section{Validity}

Two methods that have been utilized to increase the validity of the study findings are awareness of the researcher's bias and verbatim transcription of interviews. The first serves the purpose of reminding the researcher that the views of the participants are what the researcher is striving to comprehend and interpret, and not her own. The second functions as a protection tool for the participant and the researcher. The participant has the assurance that the words he has carefully chosen to convey his meanings are the same 
ones used by the researcher, and the researcher can rely on the transcriptions to check on accurate information as often as needed.

There is no set formula that if followed thoroughly guarantees the validity of the conclusions of this study. As Maxwell (1996) explains, a reliable approach to increase the trustworthiness of any study is to address the "validity threats" (p.88), or the ways the researcher could be mistaken. In this study, this researcher used three additional strategies suggested by Maxwell to strive for trustworthiness in the conclusions: searching for discrepant evidence and negative cases, feedback, and member checks ( $\mathrm{p}$. 93-95).

The information was gathered and thoroughly analyzed. The researcher did not find any discrepant evidence and negative cases. Feedback from people who are familiar with this study as well as people who are distant from it was also used as a strategy to address validity threats. As data came in, the researcher shared her findings with her peers to maintain coherence in her thinking process and gain perspective from individuals who are not as close to this study as she is, and therefore are able to perceive relevant information or nuances that she may not have noticed.

Finally, since all participants of this study were Portuguese-only speakers and the transcript and findings are written in English, the researcher contacted the participants for a verbal member-check once the findings began to emerge to ensure their points of view have remained intact. In a study about maternal response to intrafamilial child sexual abuse, the researcher conducted member checking by giving "feedback to these mothers about interpretations of the interviews in order for them to elaborate further and to clarify 
issues." The researcher adds, "the feedback loop between researcher, participants, and peers debriefers supported the interpretations of the data" (Alaggia, 2002, p. 44).

\section{Generalizability and Representativeness}

Using the logic of qualitative inquiry, I am more interested in understanding in depth the experiences and perspectives of diverse individuals than being able to generalize those experiences to a large population. Giampietro Gobo (2004) successfully attenuates the importance of generalizability in qualitative research by claiming that although qualitative sampling or non-probability sampling (convenience, purposive and snowball) lacks the ability to determine the occurrences to the total number of possible occurrences when comparing his sample to the general population, the qualitative researcher is capable of focusing on what is unique and particular to the population he or she is studying. Therefore, as long as the researcher is being as specific as possible on the sampling criteria and he or she is not claiming to generalize his findings beyond his sample, there should not be a risk of developing "empirically shallow research" (p. 443).

When discussing representativeness, Gobo (2004) advises the inexperienced researcher to "look at the variance of the phenomenon under the study. If it is high, you need many cases in order to include in your sample each category or class of your phenomenon. If its variance is low you need few cases; sometimes one case could be enough" (p. 444). Considering that this study has its focus on the correlation of urbanization and cultural globalization and father-son's intrafamilial conflicts, it is safe to affirm that the variance of the phenomenon being studied is low since the sample chosen will be able to represent the general public when it comes to people's exposure to urban 
lifestyles and the existence of conflict in every household. Although this researcher is not proposing to generalize the particular experiences of the families interviewed, such as causes of conflict and ways to resolve it, it is the researcher's belief that other families in the general population will share general experiences related to intrafamilial conflict, such as the existence of post conflict feelings and structural changes in the family.

\section{Data Analysis}

The data gathered from the interviews were analyzed inductively following the recommended steps of grounded theory specialists Strauss and Corbin (1990). Following the interviews and their verbatim transcription, the researcher used the method of "open coding," which means finding concepts for each phenomenon present in the data, and then the researcher grouped similar concepts together. The third step was to describe the properties of each category and their dimensions. After the open coding process was

finished, the next step was axial coding, which is the process of establishing a relationship between categories in order for a theory to emerge (1990). Chapter 6 combines the identified categories and develops into the main theory. The seventh and final chapter identifies the limitations of the study and offers recommendation for future research. 


\section{Chapter 6: Research Findings}

The purpose of this study is to explore whether Brazil's younger generation, raised during and after massive urbanization in the early 1970s and influenced by U.S. cultural globalization in the 1990 s, is experiencing a shift within the LC/HC spectrumslowly moving from high towards low context — and whether this shift is affecting intrafamilial relationships between generations that identify with conflicting systems. The following research questions guided the study.

1) Is Brazil's younger generation-born after massive urbanization in the early 1970s and influenced by the U.S. cultural globalization in the 1990sexperiencing a shift within the LC/HC spectrum?

2) Does this shift affect intrafamilial relationships between generations that identify with different systems?

3) Who is the cordial man now and can he adapt to a world that is becoming more dissimilar to his rural and patriarchal native habitat?

Ten adults - five fathers (Francisco, Geraldo, Antônio, Tomaz and Saulo) and five sons (Haroldo, Eduardo, Paulo, Julio and Samuel) —were interviewed and, through open coding, 117 different themes emerged. Similar themes were merged and then grouped under broader main categories. As a result of a careful analysis of the interviews, three main themes emerged: mechanisms of technological and cultural globalization, the effects of technological and cultural globalization on the family unit, and the persistence of the cordial man. Since these themes are directly related to this 
research's guiding questions, the findings are presented in forms of answers to each of the questions. Table 1 is a general summary of the findings.

Outline of Findings

I. Mechanisms of technological and cultural globalization

A. The influence of television and the Internet

B. Wider access to information and world connectivity

C. The increase of consumerism

II. The effects of technological and cultural globalization on the family unit
A. Family values versus individual values
B. Reconfiguration of the family unit
C. The lack of mindful contact between family members living in the same household

III. The persistence of the cordial man
A. Cordial fathers

Defined parental expectations toward the son's life

Faith-based beliefs

Saving face

Emotional reasoning

Parental interference in the son's adult life

B. Cordial sons

Meeting parental expectations

Reconciling father-son differences 
Cordial man tools

Gender-assigned roles

C. Parental support

Relying on the father

Is Brazil's younger generation—born after massive urbanization in the early 1970 s and influenced by the U.S. cultural globalization in the 1990s-experiencing a shift within the LC/HC spectrum?

When participants were asked about the effects of urbanization and globalization on their lives, nearly all responses focused on the technological aspect of globalization. The first research theme that emerged from these responses was named mechanisms of technological and cultural globalization since it addressed how the television, the computer and the Internet functioned as instruments of change in global times.

Technology has become the means to propagate low-context values deriving from foreign influences, such as the U.S. culture.

Fathers and sons report sharing the feeling of digital exclusion, even if in different degrees. While these fathers - who are also grandfathers - experience "digital and technological dependence" on sons, sons report "the younger generation seem to be born technologically savvy." If sons are feeling a great generational difference with regard to the way the younger generation handles information, fathers are naturally experiencing a greater gap between their generation and the generation of their grandsons. Thus, based on the responses regarding the effects of technological and cultural globalization, there is a shift happening within the LC/HC spectrum, slowly moving from $\mathrm{HC}$ towards LC. 


\section{Theme I: The effects of technological and cultural globalization}

Regarding the effects of technological and cultural globalization, fathers and sons reported noticing changes concerning the influence of television and the Internet on the household, wider access to information and world connectivity, and the increase of consumerism.

A. The influence of television and the Internet. The influence of television, especially the very popular Globo network, on the lives of Brazilian citizens has been extensively documented (Ramos, 1987; Hartog, 1993; Balogh, 2002; Gomide \& Pinsky, 2004). Globo's soap operas are on air nearly every day from 3PM to 10PM and, depending on their success, they will be watched throughout the nation. The soap operas, besides providing entertainment, have the role of shaping opinions based on cultural values that are already rooted in society, but also importing beliefs and ideals that were once foreign to Brazil, such as the need for personal space and avoiding physical punishment on children. American movies and cartoons are also a powerful medium, since the national industry is still secondary when compared to the amount of American movies and cartoons, which are aired on television and watched by Brazilian families. Although television has the capability of reaching every generation under study, both fathers and sons claim that the younger generation (the grandsons) is the one being most affected by it.

Samuel (son) states:

The TV and the radio are tools to shape opinions, mostly the TV though. Our society follows what is being shown in Globo. Everything that is on TV becomes 
a fad. Our society is extremely molded by what is happening in the soap operas, in the news. Therefore, the way people raise their kids is changing. The way people look at life is also changing.

Francisco (father) sees the television as an educational tool:

I am sure the TV has influenced people to change because everything is on TV nowadays. In the past, the information was not there so you could not demand anything. Nowadays, if you see something wrong on TV you can demand the right thing to be done. I do that with my kids and they do the same with me. If I am being too harsh when punishing them, they will watch something about it, and soon they tell me that a father must not hit a son or treat a son in such manner. Haroldo (son) is a father as well and shares his feelings of impotency with regard to the influence television has on his child:

There is no way you can take the TV away from a child. They know everything that is going on at such a young age. My son said he would call the police if my wife left us and would tell them she was trying to abandon him.

Regarding the effects of the Internet, most fathers report "being dependent on sons" and "feeling excluded from digital inclusion." Although all sons are in their twenties and thirties and all have been in contact with technology for most of their lives, there was an unanimous belief that they were the last generation that experienced unsupervised play time outside the house. Seven participants, four fathers and three sons, reported some sort of preoccupation with the grandson's generation and its relationship 
with technology. Samuel (son) compares the way he interacted with friends and the way children interact with friends nowadays:

The Internet has changed the world. When I had to talk to a friend I had to call him or go to his house. Kids nowadays spend their days chatting online. Before parents knew with whom their children were talking to and what they were talking about, the silent conversation that exists today was not there then. Eduardo (son) sees differences in the way his much younger brother relates to technology. Not only he sees his brother as possessing more knowledge on how to deal with the computer, but he also believes that his brother would not mind being grounded at home with his technological gadgets.

My little brother is way more computer savvy than I am. When I was his age, I did not know much about computers. Nowadays if my brother has any problem at school, my father will ground him and will say that he has everything he needs at home. It is easier to keep the child grounded in the house.

B. Wider access to information and world connectivity. As I mentioned in the literature review chapter, wider access to information and world connectivity define cultural globalization. Many fathers and sons are observing and/or experiencing the changes brought by both phenomena. Julio (son) talks about how children and teenagers are no longer dependent on parents and teachers to educate them.

... Technology has allowed information to come from multiple sources. In other words, the amount of information that you have regarding education, about what 
is right and what is wrong, what you can and can't do, what is healthy and what isn't, is overwhelming.

Geraldo (father) and Tomaz (father) express their concerns with the "dumbing down" of societies due to the shortcuts brought by technology. Tomaz (father) claims that the "evolution of technologies is producing an acceleration in the amount of knowledge that one can have. However, most knowledge that people choose to acquire is useless." Saulo (father), who has a positive outlook on globalization and technology, contrasts the present with the past:

Nowadays, the youth take the wrong path only if they want because information is available everywhere. There is an explanation for everything, from what is right to what is wrong. It was not like that back then. People would not explain things to you; you had to find things out on you own.

It is challenging nowadays to keep information from spreading. Samuel (son) talks about the influence of the new social media, such as Facebook. A post, photo or video can become viral and travel the world in seconds. He states, "Familial conflict has become an open debate. If I post something online saying my dad is tough, soon there will be people I don't really know giving me advices on what to do."

Paulo (son) summarizes the phenomenon of global connectivity: "If you have Internet, you have all the information you need. If something happens in Japan, in seconds you will know about it."

C. The increase of consumerism. Participants in this study often discussed the importance currently given to material possessions. Geraldo (father) connects 
consumerism to the sense of immediate satisfaction felt by the youth and blames U.S. culture for the dissemination of such values.

The youth feels the weight of consumerism and immediacy. It feels like our responsibility is to make stuff instead of transmitting knowledge. Kids will say that you are boring [if you are trying to teach them something], that they can't look at it [books] anymore. We know what they don't want, but we still don't know what they actually want. Better yet, we do know, they want things that don't require hard work from their part; they want immediate satisfaction. My profession is to read history and see what has been done to our Brazilian culture. U.S. colonialism has been absurd in every sense. Our values are gone. U.S. acculturation... globalization... They wanted to sell us the idea that every boy must have a computer, must have a cell phone and other electronic gadgets. My kids were not raised like that [buying everything they wanted] and are not traumatized because of it.

Haroldo (son) finds a circular connection between work and consumerism. He states, "He works in order to buy things to go to work." Once he buys good clothes and shoes, he buys a car and other goods to be able to be presentable at work. Paulo (son) reflects, "I see this happening with my friends. I have one friend that works and spends all his earnings because he has to have that certain brand. It is all about consumerism." Tomaz (father) finds a difference between the behavior that his generation displayed toward foreign brands and the behavior of the youth now. 
Here in Brazil we only had bad jeans to wear, so we would try to import Lee, Levi's. It was hard to get them here but when we did we would remove the tags because I was so against it, and to this date I am still against becoming a billboard for these companies. Nowadays people pay exorbitant prices to advertise these brands. We were different! We were counterculture!

\section{Does this shift affect intrafamilial relationships between generations that identify with different systems?}

Participants' responses indicate a contrast between fathers' emphasis on group oriented/collectivistic values and sons' needs to make individual choices. While fathers claim that sons must think about the family before acting, sons claim to have acted in an individualistic manner and that such individuality has either "caused conflict within the family realm" or was perceived as an "act of selfishness."

Although this research was designed to focus solely on two generations, the generation of the grandsons frequently emerged from participants' responses and became part of the intergenerational dynamic under study. Similar to the HC-LC continuum, fathers and sons' responses regarding intrafamilial values and behaviors seemed to be in a continuum as well: fathers being at the higher end of the $\mathrm{HC}$ continuum, sons being in the middle, and grandsons at the lower end of the HC continuum. While fathers and sons agree on what has changed within the family realm - mixed families, divorces, remarriages and lack of mindful contact between family members - they differ in the degree of normality they attribute to these situations. Thus, based on participants' responses regarding familial dynamics, their families have been affected by technological 
and cultural globalization; and family expectations, which were once unquestionable, are beginning to be challenged by the younger generations.

Theme II: The effects of technological and cultural globalization on the family unit

This theme emerged from participants' narrative on their personal experiences of being a part of a family unit and also from their viewpoints regarding the current situation of families in general. All five fathers reported having clear expectations with regard to family values while four sons_-Julio, Samuel, Eduardo and Haroldo-reported having acted based on their individual needs. Other reported issues were the "reconfiguration of the family unit," the "lack of mindful contact among family members living in the same household."

A. Family values versus individual values. Fathers who have been immersed in a high-context culture longer and have been less exposed to individualistic values that accompanies cultural globalization report feeling "unheard," "disrespected," "lied to," and "paid no attention by" their sons prior or in times of conflict. Sons' lack of gratitude is also a subject that many fathers brought up. Some fathers feel that the conflict has not been resolved and choose to avoid the subject as the best alternative to maintain their social relations harmonious. Sons, on the other hand, have to manage their shifting values with their desire to partially meet parental expectations. Tomaz (father) illustrates the contrast between group/family values and individual needs:

When you are born, you may want to do crazy things throughout life but you have to think about those who stand behind you. When you are born in a family unit and you display inadequate behavior you are directly affecting the rest of your 
family. You don't have this right; you will affect other people. If you were alone, without any descendants or ascendants and if you wanted to die, then I think you have the right.

Here Samuel (son) talks about how he was treated by his mother after he had deviated from familial values:

My mother ignored me, she made me so angry at her. I don't like people like that. It [the way she ignored him] made me really angry. If she smokes, she is harming her own lungs; there is no reason for me to ignore her. I have the right to do what I please with my life. Ignoring comes from the word ignorance. It is wrong. Julio (son) recalls a time when he felt his family was punishing him for wanting to be independent:

This may sound crazy, but it felt like I had to be punished [by my family], pay a fee because I was successful. The problem did not reside in being successful; it resided in the fact that I was successful after I became independent [from them], after I became individualized.

Trying to establish an individual identity, one that separates or complements the identity built within the family realm can be challenging, especially when fathers expect their sons to absorb and live by family values.

Francisco (father) states, "The family is sacred and we must take care of it." Geraldo (father) claims, "Your place [son's] is next to your mother and father... here is where you will learn things." Tomaz (father) adds, "We are where we are [as a society] not because of technology but because of family, because of unity." Antônio (father) 
believes that "the reason we [himself and his sons] got married and constituted a family is to raise a child like I was raised." Saulo (father) states, "Everything stems from the family nest. The foundation of everything is the family. From there you are ready to deal with the outside world. Without family there is no foundation."

B. Reconfiguration of the family unit. Geraldo (father), Antônio (father), Saulo (father), Tomaz (father), Paulo (son) and Julio (son) affirmed they have seen major changes in the familial dynamics due to the assimilation of global values and access to technology. The two major changes these participants mentioned are the reconfiguration of the family unit and the lack of mindful contact within the household. When referring to the reconfiguration of the family unit - divorces, re-marriages, mixed families and single parenting - fathers, unlike sons, see this phenomenon negatively, displaying resistance and unacceptability. Geraldo (father) states:

There is no commitment and permanence in the relationship between parents nowadays. The child is born, and I don't know how... if I had to live like that, I would have gone crazy. I couldn't live with a woman that has three children from different fathers. How will one man look at the child of another man? This is something I can't understand. It does not make sense to have a child and to not be there to take care of this child. Responsibility and authority is what is lacking nowadays.

Saulo (father) makes a connection between the lack of family structure and the misfortunes that can affect the life of a young person. 
A lot of the bad things we see around are happening because there is a lack of family orientation. There are many families going through tough times when the kids are acting up, the parents are fighting a lot and if they end up separating, and then it gets worse: kids leave home, they begin to make poor choices, like drugs, and end up in trouble or even dying.

Paulo (son), despite sharing the same sense of loss that fathers have expressed, see this reconfiguration of family as a phenomenon that has been present in his life for a long time.

I think that what is missing nowadays is something I had at home while growing up: Where are you going? When are you coming back? What did you do? Who did you go with? For a long time now, this is disappearing because the family unit has become unstructured a long time ago.

Julio (son) believes we will only be able see the effects of technology and globalization on the family unit when this new generation of reconfigured families "grow up, get married and have children. Maybe they will try to move backwards: have dinner together, be around family. I don't know what the future holds."

\section{The lack of mindful contact among family members living in the same}

household. Francisco (father), Antônio (father), Tomaz (father), Julio (son), Eduardo (son) and Haroldo (son) expressed their concerns regarding the lack of mindful contact among family members within the household. By lack of mindful contact, participants referred to the growing absence of family gatherings in which individuals were mentally and emotionally present in the moment, and not only physically present, or multitasking 
by watching television or using the computer. Some common used expressions were:

"There is no dialogue anymore"; "The relationship is becoming impersonal"; "Kids are computer addicts"; "Each person in the family is doing their own thing"; and "Everyone is in their own cave."

Tomaz (father) compares the effects of technology on the family realm to a knife: Things are bad. I am worried and that is why I try to have meals with my family, sit together. I am trying to keep our animal instincts alive. The day that we are only moved by rationality things will get worse. If the family sticks together we will be able to protect one another. Knowledge is good, technology is good, but if you don't know how to use them, they are no good. A knife can be used in a surgical procedure as it can be used to kill. It depends on who is holding it and on the type of instruction this person has had.

Results indicate that these families are going through a process of change. In a high-context/collectivistic_-low-context/individualistic continuum, fathers would be placed on the higher $\mathrm{HC}$ side, where family values and emotional ties are highly regarded. Sons would be placed a little lower, slowly integrating individuality into their own set of values. Grandsons, on the other hand, may be the ones affected the most by the technological aspect of globalization. The younger they are, the more they are dependent on technology and the more they value their personal space.

\section{Who is the cordial man now and can he adapt to a world that is dissimilar to his rural and patriarchal native habitat?}


The cordial man is the Brazilian personification of high-context characteristics. Besides permeating the public arena, as seen in the literature review chapters, the cordial man is also present in the most private circumstances of the participants of this study: their familial interactions.

As expected, the interviewed fathers operate within the cordial man mind frame. They expect sons to live by family values, are preoccupied with the image of the family by the community and rely on emotional reasoning as a tool for persuasion. Sons, against my previous belief, are also cordial men themselves, even if at a lower degree when compared to fathers. Although sons have become more individualized, familial harmony is highly regarded. Thus, the sons try to reconcile their individual needs with their fathers' expectations. In order to meet parental expectations and act according to individual values, most sons opt to avoid conflict and mask their intentions.

Holanda speculated that a power shift_-from a centralized patriarchal family to a decentralized institutional structure-would weaken the roots of the cordial man. However, the cordial man has been able to transition to an urban environment due to his reliance on personal connections and favoritism (Rocha, 2004). A globalized environment brings new challenges to the cordial man, since individuals are not being transplanted into culturally diverse cities; instead, cultural diversity is meeting individuals in the privacy of their homes through their computers and televisions.

Although cultural and technological globalization is changing the dynamics of the families interviewed, it is still too soon to determine if such a new phenomenon will be able to weaken cordial tools used within the family realm. If the cordial man remains 
strong within familial dynamics it is unlikely that he will wither in the public arena. It is through the upbringing of children, who are first influenced by parents and second by the context in which they are immersed, that cordial values are disseminated. For now, the cordial man remains alive in an urbanized and globalized world.

\section{Theme III: The persistence of the cordial man}

Although each dyad of father and son has its own unique and non-generalizable familial dynamic experiences, some common concepts related to the cordial man emerged. These concepts were found in most responses and reflect values and behaviors taught at home and reinforced by society. Relevant concepts were placed under three main categories: cordial fathers, cordial sons and parental support.

A. Cordial fathers. Five common concepts emerged from fathers' responses: defined parental expectations towards son's life; faith-based belief; saving face; emotional reasoning; and parental interference in the son's adult life. These concepts were placed under this research theme when four or more fathers mentioned the same concept.

Defined Parental expectations toward the son's life. It is difficult for parents to keep their expectations towards their sons' lives in check. Parents may be subject to seeing their offspring as an extension of themselves or as a work in progress. Results show that the fathers in the study not only raised their sons with great awareness of what was expected of them, but they also continue to express their expectations to their adult sons. Geraldo (father) states, "My [adult] son does not smoke in front of me, but he knows that I know he smokes. Once we touched on the subject, I hinted that I knew he 
was smoking. I told him: that is not what I have taught you, you know that this is not what I expected of you."

Antônio (father), who has an authoritarian parenting style, often measured the success of his children based on how similar to him they had become. "I started from nothing. So I have educated my sons to be like me, or at least to have what I have. Actually, I expect them to have more than me because I gave them the opportunity to study."

Faith-based beliefs. Faith-based beliefs were present in all of the parental discourses. Fathers either had a strong religious influence while growing up or spent part of their lives searching for the divine. Four out of five fathers report raising sons based on faith-based values. Although this is not a theme discussed previously in the literature review chapter, this concept was added here due to influence faith-based beliefs have on the moral values and social expectations of the Brazilian society. Holanda addresses religiosity on the cordial man theory to explain that Brazilians avoid distances even with religious deities by calling them by affectionate nicknames. Francisco (father) states:

I had a strong religious upbringing. My mother always taught me to be obedient [to god]. I am an evangelical protestant. I have strayed a little, but I have always relied on my religious beliefs to teach my kids right from wrong, what they should do and what they shouldn't.

Saulo (father), who is an active Catholic, points out that his children were raised Catholic. His son worked in their church as a child and that "to this date, both [children] volunteer to work at their church." 
Saving face. The importance of "saving face" within the community and the utilization of "emotional reasoning" to persuade sons were also discussed by fathers. Both concepts are characteristics of high-context societies and are powerful tools-used by the cordial man - to try to keep sons under control. Francisco (father) states:

I worry about what my [extended] family or neighbors think. It worries me. Nowadays we also live for the society. There is always someone who will be badmouthing you. And if you do something that attracts a lot of attention to you, then I don't think it is cool. It becomes vulgar. Let's say you are dating someone, and you go beyond a certain point [getting pregnant], you will attract the attention of other people, and that is not ok.

Antônio (father) echoes the same idea:

I worry about what other people think. When you have a son that is doing something wrong, everybody is going to punish you, they will be talking about your son. It is important to act right for your sake, for your family's sake, for everybody's sake. If you are not a good person, nobody will like you. Everybody will complain, criticize, point out what you are doing wrong. It would make me really sad; it would be painful to have a son that people are talking about, criticizing.

Saulo (father) is concerned with the image that one can project to other people. He claims that someone's image is important and must be cared for. So, "if someone asks who is this person, everyone will say that this is a very nice person." 
Emotional reasoning. Fathers were asked about their reaction towards sons in an extreme conflictive situation, such as drug abuse. All fathers responded they would help their sons and would use emotional appeal as a tool to persuade them. Francisco (father) states, "My kids would think about me before doing something [wrong], they would think about how I would react. I would not admit too many mistakes or foolish behavior from their part because I have never given them a reason to do that with me."

Saulo (father) adds, "We have to follow parents' advices or advices from people who are older than us. Parents always know better. In such a serious case, I would ask him to think about us, about his roots, and our tradition. We have [given him] such a good foundation that he could only have a good future with it."

Parental interference in the son's adult life. Finally, the last concept that emerged under this theme is parental interference in the son's adult life. This concept has a relevant connection to parental authority. Some fathers were naturally more authoritarian than others while raising their sons. However, all fathers indicated that authoritarianism was necessary in order to clearly establish a familial hierarchy. Thus, even the fathers who did not have an authoritarian nature had to put on the "authoritarian hat," as Julio (son) stated, in order to play the disciplinarian father and male role expected by wives and society. Tomaz (father) states:

Depending on what kind of things he is doing I would interfere because if I didn't, it wouldn't be a problem between him and I, it would be a problem between me and I because I am the most difficult person that I have to live with. I live with myself twenty-four hours a day. I can't lie to myself; I can't fool myself; I can't 
pretend that everything is all right. And in order for me to live reasonably well I have to be in peace with me and with God. So I would interfere for my own sake. I wouldn't care if he wanted me to interfere or not. After he had hit his head against the wall a little bit I would back off for a while, or would try a new approach. But the first approach would be direct confrontation, with love and support, but always going back to the imposition of authority. Francisco (father) states:

A son of mine has to respect me as a father. At their age all I have to do is talk to them and they will respect me [my wishes]. I have never given my sons the authority to disrespect me. They don't even smoke in front me, not because I am the macho, mean type, but because they learned to respect me. When they were little I just had to look at them and they would run towards me to see what I wanted. They were always afraid of the belt.

B. Cordial sons. Four common concepts emerged from sons' responses that were connected to the cordial man: meeting parental expectations; reconciling father-son differences; cordial man tools and gender-assigned roles. These concepts were placed under this research theme when four or more sons mentioned the same concept.

Meeting parental expectations. Sons were raised immersed in parental expectations and thus talked about situations in which they were preoccupied with trying to meet their father's expectations. Here Julio (son) is faced with doubt regarding the individual — and not family supported — choices he made in life: 
When I told my parents [about losing my job], I was ashamed to have let them down. It felt like I was coming to them and saying: look, I rejected that educational standard [given by his parents] and chose to pursue a different one, but then I got fired. I had to make sure they knew it was not my fault. I hadn't done anything wrong. I had to resolve this issue within me later on.

Haroldo's father expects him to raise his son like he was raised. Although Haroldo (son) agrees with his father on the effectiveness of physical punishment, he does not want to raise his child with the amount of severity that he was raised. When confronted by his father on being "too soft" on his son, Haroldo (son) blames the new Brazilian law against physical punishment on children: "Sometimes my dad complains that I am not raising my child the way he raised us. I don't want to be as harsh as he was. I tell him there is a law now so I can't be too harsh."

Reconciling father-son differences. The bond that unites typical high-context families is strong. Although these sons are moving towards individualization there is a unanimous desire to maintain the harmony of the relationship or to reconcile when there is rupture. The sons that have shared conflictive situations in which family values were challenged by individual values are rebuilding — using different tools — the once strained relationship. Julio (son) is trying to open up to his family:

I hope that in this new father-son relationship I can discuss with him my projects in life. Nowadays I am able to share with him a little more of my projects, of what I am thinking, I am able to talk about myself. Let me give you an example. I am thinking about selling my house. I offered the house to my mom in case she 
wanted to live here. I didn't offer it to my dad, but I talked about it with both of them. I asked if they were ok with me selling the house. We talked about the monetary value of the house. For the first time they were aware of how much I pay for my things, of what is the value of the things I own. I felt a little safer in sharing these things with them and asked for their opinion, finally.

Eduardo (son) was able to reconcile with his father by accepting blame and by avoiding the subject:

My relationship with my father changed since our big blowout because I learned a lesson. If I could I would change the past, I would have acted differently. Nobody likes to get hit. I was never hit as a child to see it happen when I had grown up. Sometimes I think about what happened and I feel hurt, but at the same time I think that I am the one to be blamed. If you ask my father I am sure he regrets it as well. We don't talk about this because I keep it to myself. I will ask for his advice on other things, but we don't talk about me.

Samuel (son) changed his behavior to stop hurting his father:

He [father] was not going to hit me; he wasn't going to do anything with me, except throwing at me a bunch of words. Words can't hurt. I was down and I was hurting him. I wanted to get better for him, for my family in general. Only after I stopped he decided to talk to me about things. After everything had been done.

Tools of the cordial man. Since sons are interested in reconciling with fathers but are also interested in pursuing their needs based on individual values, they have 
created tools to help them balance both interests while trying to avoid conflict. Samuel (son) prefers to smooth things over in times of conflict. He affirms he can be "manipulative" and use the jeitinho to pursue something he knows his family will be against. In the excerpt below, he has difficulty to resolve a conflict with his father objectively and prefers to mask the truth until he has accomplished what he desired. I wanted to buy a big motorcycle but I knew he [father] would not let me. I had a friend who also wanted to buy one. He had never had a big motorcycle neither did I. So we decided to buy one together. I was 30 years old then. I told my father that the motorcycle belonged to my friend, but that I would be the one to pick it up from the dealer. Then I went, got the motorcycle, came back and kept on riding it day after day. Soon my father began to ask me why my friend was leaving his motorcycle with me for such a long time. I replied that my friend didn't have time to ride the bike. Then, one day I finally told him that I had bought the motorcycle with my friend. My father asked me why I had not told him the truth? I said: If I had told you there would be a conflict between us. Thus it is better if I buy what I want and then tell you. We will get into an argument, and even a conflict emerges I will already have what I want. That is how I do things. Nowadays the motorcycle is only mine and I even give my dad a ride from work in it. It is the Brazilian jeitinho.

Haroldo (son) has been raised with emotional reasoning - also known as emotional manipulation - as one of the tools that kept him from misbehaving. He also intends to use such tool while raising his son: 
My father used to tell us that if we did anything wrong and went to jail he would not help or even visit us. He would say that just to keep us from doing anything wrong. But if you truly analyze it, you will see that he would [help and visit us]. This is the type of education that he has passed to us. I do the same thing with my kids now and will probably do the same when they grow up. I will tell them: don't do this because I have done it before or don't do this because I have never done it. You don't see your dad doing this, so why would you do it? This sort of discipline works, this pressure [works]. There are a lot of people that were raised without this pressure and are lost in this world. Some of them are not even in this world anymore. With us this [technique] worked. We drink our beers, but none of us are addicts.

Eduardo (son) did not want the conflict with his father to escalate so he preferred to avoid conflict in order to maintain a certain level of harmony:

I would avoid running into him when I was going out. I already knew at what time he went to bed and I would take advantage of that and sneak out... I was afraid of him. I was trying to avoid conflict. Even tough I did not know for sure what would happen to me when I got back from partying I would go anyway. At that moment, all I wanted was a way to get away. I wanted to go out and have fun.

Gender-assigned roles. All sons shared experiences in which they were immersed in a familial context that had defined roles for males and females. The male, paternal, "macho" figure is something taught at home and reinforced by society. In an 
honor culture, such as the Brazilian, in which masculine values are predominant, there is great inflexibility towards gender roles. Eduardo (son) states:

Things were different with my sister. When a guy wanted to date her, he had to come to our house to talk to our dad. Maybe because she is a woman he [dad] was not as tough on her as he was on me. Maybe because women are less defiant she did not get into a lot of trouble with him as I did.

Paulo (son) claims, "The difference [in the way siblings were raised] is that my parents were more strict with my sister; maybe because she was the firstborn or maybe because she is a woman. There a strong cultural influence saying that women have to act differently."

Haroldo (son) and his wife have different disciplinary roles:

If a child does not fear his father, then you have a problem. Fathers have more of a disciplinary role than mothers. When my wife talks to him [son], he doesn't change his behavior or he will talk back. But if I am the one speaking to him he will stop what he is doing right away. My wife always counts on me to discipline him. He remembers the spanking I have given him and stops right away. Julio (son) talks about his father having to act on the role of the disciplinarian father. After his mother had tried different and ineffective disciplinarian tools, his father would step in. "He wasn't the one to judge the offense. He would execute the final punishment. He had to put on an act. I could see he did not like that and he felt bad for having to do it." 
C. Parental support. Father-son relationships have changed from one generation to the other. These were some of the expressions used by fathers to describe their childhood: "Children had no voice," "I had a strict work schedule to help my family," "there was a set hierarchy at home," "I had to leave the room when adults were talking," and "I had to count only on myself." None of the fathers interviewed shared an occurrence of having deviated from their parents' expectations, of causing any disappointments to their families or of relying on their families once they left home. Sons, on the other hand, despite being raised by fathers with an authoritarian parenting style were able to pursue their individual interests and beliefs. These sons did not like to disappoint their fathers but they were also not willing to abstain from pursuing what they perceived as necessary, thus the need for some sort of reconciliation.

Relying on father. This concept emerged from fathers and sons' responses and it is pivotal in understanding why sons - differently from their fathers — were able to act based on individualistic values despite familial expectations, and why fathers still influence sons' attitudes.

When sons were asked about their father's reaction if they were to transgress a serious familial expectation, such as drug abuse, all sons responded they could "rely on father to be helped." Despite all the conflicts and behavioral deviations reported by sons, all of them were welcomed back into the family realm. Fathers not only responded, they would help their sons in times of need, but most of them is presently supporting their children either financially or in raising their grandchildren, which enables their interference in sons' life. 
Geraldo (father) states, "A lot of people question me about having 30-year old children living with me. I tell them: Where do you want my children to go? Should they live on the street? Having my children with me is not a burden."

Francisco (father) states:

You guys [the generation of his son] take more risks; do things I wouldn't do. I never did those things because I did not have the same [parental] protection that he [son] did. I did not have a father and a mother [to catch me if I fall] like he did. Kids nowadays count on the familial support a lot. If a son goes to jail, there goes the father to rescue him. I did not have that. I was afraid of doing anything wrong because there wasn't anybody to save me. By the time I was 18 , I was the one taking care of my mom.

Tomaz (father) and Saulo (father) support their children by taking care of the grandchildren on a regular basis or when needed. "I already foresee that we will end up having to take the grandchildren and pick them up [from school] depending on the day," says Tomaz (father). "My daughter is always here because we take care of our granddaughter for her while she works," says Saulo (father).

\section{Chapter Summary}

Three principle questions guided this study: first, is Brazil's younger generationborn or raised after massive urbanization in the early 1970s and influenced by U.S. cultural globalization in the 1990s - experiencing a shift within the LC/HC spectrum? Second, does this shift affect intrafamilial relationships between generations that identify 
with different systems? Finally, who is the cordial man now and can he adapt to a world that is becoming more dissimilar to his rural and patriarchal native habitat?

The ten participants in this study discussed shifts brought by technological and cultural globalization and its effects on familial values. They also discussed the dynamics of their father-son relationships. Three research themes emerged and were directly related to the research questions, thus were organized as responses to each of the questions.

The first research theme regards the mechanisms of technological and cultural globalization. Fathers and sons reported noticing changes concerning the influence of television and the Internet on the household, the increase in information access and world connectivity, and the increase of consumerism. Fathers and sons report feeling digitally excluded when they compare themselves to younger generations.

The second theme focuses on the effects of technological and cultural globalization on the family unit. Participants' responses indicate a shift within the value system of the sons interviewed. Sons have pursued goals based on individualistic values that challenged familial expectations. The subjects of the study also addressed the subsequent generation (i.e., grandsons) for comparative purposes. Similarly to the HCLC continuum, fathers and sons' responses regarding intrafamilial values and behaviors seemed to be in a continuum as well: fathers being at the higher end of the $\mathrm{HC}$ continuum, sons being in the middle and grandsons at the lower end.

Participants shared viewpoints regarding changes happening within the family unit: mixed families, divorces, re-marriages. However, since sons have been exposed to 
such phenomenon longer they tend to see the reconfiguration of the familial structure with a higher degree of normality when compared to fathers. Another subject brought up by participants was the lack of mindful contact among family members, since people can be physically in the same household but each member will be isolated with the help of technology. For participants such behavior can weaken family ties and lead to disconnected families.

The third research theme concerns the cordial man and parental support. Relevant concepts were placed under three main categories: cordial fathers, cordial sons and parental support. Results show that fathers and sons operate differently within a cordial man mind frame, and that there is no separation between social and familial cordial behavior. Emotional reasoning, conflict avoidance and "machismo" were some of the concepts brought up by the participants of this study when talking about their familial dynamics. These are the same tools used within the Brazilian society as seen in the literature review chapter. Although the individualization that is being brought by technological and cultural globalization is presenting new challenges to the survival of the cordial man, he is far from withering. Cordial man behavior is circular: it is taught at home and supported by society. Additionally, sons are more financially dependent on their families now than they were in the last generation. Such dependence creates an additional bond between fathers and sons in which fathers feel entitled to interfere in their sons' adult lives and sons feel a greater need to meet parental expectations. 


\section{Chapter 7: Discussion and Conclusion, Limitations, Recommendations}

The research uncovered themes related to intergenerational dynamics in an urbanized and globalized context. This chapter discusses findings and the conclusions of the study. The emerging theory is evaluated using the criteria suggested by Strauss and Corbin (1990). Finally, the implications for practice, limitations and recommendation are addressed.

\section{Discussion and Conclusion}

The study of cultural variability is currently being challenged by porous boundaries between culturally diverse groups. Technology, wider access to information and global connectivity function as bridges for cultural exchange. Although values and behaviors are exchanged and assimilated by everyone involved in a cultural transaction, there is a constant imbalance among cultures. Economically developing societies tend to import cultural values from economically developed societies at a higher rate. Thus, as history repeats itself, it is only natural that peripheral cultures admire and wish to adopt practices of central cultures. Most low-context cultures belong to the developed group of nations and most high-context cultures are also considered under developed or developing nations.

Brazil, a HC and developing nation, is still pursuing horizontal digital inclusion. The knowledge of how to use computers and the Internet remains a privilege of the middle and upper classes and the younger generations. Such familiarity with computers comes at a price in a culture accustomed to prioritize family gatherings. The fathers and sons interviewed reported noticing changes within their families due to the use of 
technology. Although fathers and sons are not novices in the effects of the television within households, the same cannot be said about the effects of the use of computers and video games. This is a relatively new phenomenon to these fathers and sons. Sons are raising their children with the help of electronic devices since they keep children busy and out of trouble. Furthermore, this is a time in which both parents choose or have to work to support the family.

Families are also experiencing the individualization of leisure and play time. Family members may be physically present but are mentally absent. Mark Federman (2004), a chief strategist from the McLuhan program in culture and technology, confirms such separation between mind and body:

“In cyberspace, we literally go 'out of our minds', not to insanity, where we lose our sense of reality, but to an extension of reality that offers us many more dimensions of experience. As McLuhan predicted, 'having extended ... our central nervous system into the electromagnetic technology, ... [we] transfer our consciousness to the computer world as well"' (p.6). In this sense, computers, video games, and the Internet can be providers of experiences that differ from the ones that the familial reality is able to provide. These technologies also function as a safe place to which family members are allowed to escape: for children, this is a safe place in their sheltering home; for adults, such technologies are often connected to work.

Another intrafamilial change reported by fathers and sons is concerning conflicts generated by sons' attitudes based on individual needs, which confirms a minor shift from $\mathrm{HC}$ to LC in sons' reasoning. While fathers highly regard familial values, sons are 
in a transitional state, in which individual goals are relevant enough to challenge parental expectations, but still cause guilt when pursued. Due to such guilt and the desire to maintain a healthy familial relationship, the sons will try to reconcile with their fathers. Reconciliation can be achieved through conflict avoidance or through the use of cordial man tools, such as masking the truth, smoothing things over, indirect communication and the use of the jeito.

The utilization of cordial man tools at home - specially the jeito- has not been the focus of academic research. Roberto DaMatta (2004) addresses the family realm by contrasting the familial and private dynamics at home against the public and impersonal characteristics of the street in order to explain why Brazilians use the jeito frequently:

The street compensates home, and home equilibrates the street. In Brazil, home and street are the two sides of the same coin. If home bases itself on a set hierarchy with people positioned according to their importance, sex and age, constituting basic dimensions in this classification - first the father (the 'boss of the family'), then the children and, lastly, the 'housewife'-, the street fundaments itself on the equality of everyone with regard to the law, to the stop signs and to the a public order that wishes to become more democratic. However, as these values do not change by decree, home and street continue to be- - as once said Gilberto Freyre - intimate and complementary enemies. Thus, what is lost in one side is gained in the other. What is denied at home-impersonality, equality and work - is available on the street. In Brazil, the world would make no sense without the contrast between home and the street (p. 18). 
Although DaMatta (2004) accomplishes his purpose of contrasting private and public spaces in order to shed light on social behaviors inherent of Brazilian society, he fails to acknowledge the complexity of the familial arena by treating it as a social oasis where masks are unrequired due to the emotional rules that govern such environment. It is exactly because of these emotions that the cordial sons interviewed felt the need to mask their defiance toward familial expectations with cordiality. The familial arena functions as a microcosm of the social and public environment. Power distance is maintained due to set familial hierarchy but it does not keep sons from pursuing their individual needs. Thus, tools such as jeito, are used to ask for forgiveness, not permission.

Besides hierarchical respect and emotional ties, there is a third element that kept the sons in this study from straying from familial expectations: a relationship with parents based on obligation and reciprocity. Lia Zanotta Machado (2001) states that the apparent transformation brought by urbanization and globalization, of large and patriarchal families into nuclear and small families hides a strong supportive network made of relatives: "children are often left under the care of relatives... always is the name of the rules of reciprocity — give, receive, and requite. The perception of a relational whole precedes individualization tendencies..." (p. 20).

While sons reported acting in individualistic or defiant ways, which is one of the signs of low-context cultures, there has not been evidence that suggest they have changed their communication styles toward their fathers. Instead, cordial sons continue to perpetuate ritualized interactions by employing characteristic strategies. The main 
conclusion is that technological and cultural globalization is bringing changes to familial dynamics, but the familial collectivistic ties of participants remain strong in the face of new challenges.

\section{Emerging Theory}

Grounded theory was selected to frame this research due to its ability to generate theory according to findings from the data. As seen in the methodology chapter, Strauss and Corbin (1990) advise researchers to check their findings against four central criteria to learn if it is a well-constructed grounded-theory: fit, understanding, generality, and control.

The theory that emerged from this research is that cultural globalization is exporting individual values to collectivistic cultures, but strongly rooted family values and guilt prevent sons from becoming more individualized and disengaging from the expectations of their parents. This theory meets the criteria of being fit and understanding since it derives from the collected data and, through member-check, was verified against the beliefs of the participants of this study. This theory is general since it could be tested against individuals of other high-context cultures who may be experiencing a shift in their value systems in comparison to their families. Finally, this theory meets the control standard since it is specific enough that could be used by professionals working with families to which parental expectations and guilt are relevant familial issues.

\section{Implications for Practice}


The main implication for practice from my research is for families in conflict as well as professionals who address the family realm as their main line of work. Of special concern are family therapists, counselors, mediators and facilitators. Conflict is a natural occurrence within families and can be a healthy process that promotes a better understanding of the viewpoints of the ones involved in such conflict. If families could learn to analyze their conflict through a more comprehensive perspective it would be helpful in dissipating the tensions between conflicting parties that often are based on the right versus wrong dichotomy. In times of conflict it is difficult to step back from the heat of the moment and look for values and beliefs that are informing such behavior or such choices of words. However, families would benefit greatly if they could be trained to spot the belief that is motivating a certain action, and work on understanding the belief in greater detail before engaging in unproductive conflict.

Families could also benefit from working on strengthening the ties of the fatherson relationship. The findings of this research show that the father-son relationship is being challenged by individualistic values since technology is playing a major role in educating children and also functioning as a relevant medium for social connections. Furthermore, the time that one spends on technological gadgets is interfering with family time, which is capable of changing familial dynamics. Thus, if the uncoupling of the father-son relationship is a possible threat to the familial structure, families would benefit from learning new tools to strengthen their relationship in a modern and globalized world. 
The conclusions from this study have broad appeal to family therapists, counselors, mediators and facilitators. The effects of cultural and technological globalization on the family unit should be discussed with families during sessions and, when needed, tools to address such technological dependence should be discussed as well. Family therapy can be enriched by discussing internal values that different generations within the family abide to and by examining conflict resolution strategies that welcome differences. It is not uncommon for family therapists, counselors, mediators and facilitators to work with bi-cultural families or families who identify with different cultural values. Thus, the professionals above can benefit by applying the conclusions from this study when working with families who identify with low-context and highcontext values simultaneously.

In summary, since all of us are more exposed to different cultures due to cultural and technological globalization, the conclusions of this study have broad appeal to those who work in bi- or multi-cultural settings, such as in social agencies, schools and universities, religious organizations, community and professional groups.

\section{Limitations}

A variety of questions could have been asked to clarify the impact of globalization on participants' familial dynamics. Since there was only one question that addressed such phenomena, and it was placed at the end of the questionnaire, the issue was not properly explored. Additionally it would have been interesting to learn, in greater detail, how the sons are raising their own children and which values they are choosing to transmit to the next generation. 
It would also have been helpful to explore the dimension of masculinity in this study. Sons may be dealing with the necessity of adhering to different masculine roles at home and at work. At home sons find themselves in a transitional state-pursuing individual goals while conforming to parental expectations - but no data was collected regarding the behavior of the sons at work. It would have been interesting to learn if the sons abide to a more low-context value system in their professional environment. If women had also been interviewed there could be a comparison between man and women in correlation to low-context and high-context values.

\section{Recommendations}

In order to gain more diverse data, it would be useful to add a third generationthe grandsons - to future research. The findings of this thesis indicate that the grandsons are the ones exposed the most to technological globalization, thus it would have been interesting to learn from this younger generation their perspective on familial values and individualistic versus collectivistic behaviors.

It would also be interesting to learn about child raising intentions of the sons that participated in this study and how they are fathering their children in comparison to the way they were fathered. Such information would allow a more comprehensive comparative study between fathers and sons with regard to the values each group choose to transmit to its children.

Furthermore, a comparative study on sons' who depend on fathers, financially or to take care of grandchildren versus sons who are independent from familial obligation, 
would also be interesting to pursue in order to learn if the second group demonstrate greater individuality and other low-context characteristics. 


\section{References}

Abreu, C. (1924). Capitulos da História Colonial [Chapter of Colonial History]. Fundação Biblioteca Nacional. Retrieved October 20, 2012, from http://www.dominiopublico.gov.br/download/texto/bn000062.pdf

Agassiz, L., \& Agassiz, E. (1995). The Education of Men and Women. In Summ, H. (Ed.), Brazilian Mosaic: Portraits of a diverse people and culture (pp. 72-75). Lanham, MD: Rowman \& Littlefield.

Alaggia, R. (2002). Balancing acts: Reconceptualizing support in maternal response to intra-familial child sexual abuse. Clinical Social Work Journal, 30(1), 41-56.

Andrade, O. (1978). Do pau-Brasil à antropofagia e às utopias [From Brazil wood to anthropophagi and atopias]. Brazil: Editora Civilização Brasileira.

Armstrong, P. (2000). The Brazilianists’ Brazil: Interdisciplinary portraits of Brazilian society and culture. Latin American Research Review, 35(1), 227-242.

Azevedo, F. (1995). Altruistic, sentimental and generous. In Summ, H. (Ed.), Brazilian Mosaic: Portraits of a diverse people and culture (pp. 211-226). Lanham, MD: Rowman \& Littlefield.

Balogh, A. M. (2002). O discurso ficcional na TV: Sedução e sonho em doses homeopáticas [The fictional discourse in television: Seduction and dreams in homeopathic doses]. São Paulo, Brazil: EdUSP.

Barbosa, L. (1992). O Jeitinho brasileiro: A arte de ser mais igual que os outros [The Brazilian way: the art of being more equal than others]. Rio de Janeiro: Editora Campus. 
Bezerra, E. (2004). Três retratos de Manoel Bandeira [Three pictures of Manoel Bandeira]. Brazil: Academia Brasileira de Letras.

Bishop, E. (1995). The Usual Moderation. In Summ, H. (Ed.), Brazilian Mosaic: Portraits of a diverse people and culture (pp. 128-129). Lanham, MD: Rowman \& Littlefield.

Borges, D. (1994). Brazilian Social Thought of the 1930's. Luso-Brazilian Review, 31(2), 137-150.

Cândido, A. (1998). Sérgio Buarque de Holanda e o Brasil [Sérgio Buarque de Holanda and Brazil]. Brazil: Editora Perseu Abramo.

Cardoso, F. H. (1999). Prefácio. In Lampreia, L. F., Diplomacia Brasileira [Brazilian Diplomacy] (pp. 415). Rio de Janeiro: Lacerda Editores.

Cervellini, S. (2006). Corrupção na política: eleitor, vítima ou cúmplice? [Corruption in politics: voter, victim or accomplice?]. IBOPE Inteligência. Retrieved October 04, 2012, from http://portalnlb.ibope.com.br/ptbr/conhecimento/artigospapers/Documents/08_Corrupção_na_Pol\%C3\%ADtica_ Eleitor_V\%C3\%ADtima_ou_Cúmplice_Silvia\%20Cervellini.pdf

Chinese Culture Connection (1987). Chinese values and search for culture-free dimensions of culture. Journal of Cross-Cultural Psychology, 18, 143-164.

Chu, R. A. \& Wood, T., J. (2008). Cultura Organizacional Brasileira Pós-Globalização: global ou local? [Post-Globalization Brazilian Organizational Culture: global or local?]. Revista de Administração Pública, 42(5), 969-991. 
Cohen, D., \& Leung, A. K. Y. (2010). A CuPS (Culture Person Situation) perspective on violence and character. In P. R. Shaver \& M. Mikulincer (Eds.), Human aggression and violence: Causes, manifestations, and consequences (pp. 187200). Washington, DC: American Psychological Association.

Cohen, D., \& Leung, A. K. Y. (2011). Within- and between-culture variation: Individual differences and the cultural logics of honor, face, and dignity cultures. Journal of Personality and Social Psychology, 100(3), 507-526.

Corneau, A. (Director) \& Sarde, A. (Producer). (2003). Fear and trembling [Motion picture]. France and Japan: Image Entertainment.

Couto, R. (1932). El hombre cordial, Producto Americano [The cordial man, An American product]. Epistolario. Monterrey, Mexico.

Croucher, S.M., Bruno, A., McGrath, P., Adams, C., McGahan, C., Suits, A., \& Huckins, A. (2012). Conflict Styles and High-Low Context Cultures: A Cross-Cultural Extension. Communication Research Reports, 29(1), 64-73.

DaMatta, R. (1991). Carnivals, rogues and heroes: An interpretation of the Brazilian dilemma. (J. Drury, Trans.) South Bend, IN: University of Notre Dame Press.

DaMatta, R. (1994). Conto de mentiroso: Sete ensaios de antropologia brasileira [Liar's tale: Seven essays on Brazilian anthropology] (2nd ed.). Rio de Janeiro: Editora Rocco.

DaMatta, R. (2004). O quê é o Brasil? [What is Brazil?]. Rio de Janeiro: Editora Rocco. 
Dias, M. O. (2000). A Família numa Sociedade em Mudança: Problemas e Influências Recíprocas [The Family in a Changing Society: Reciprocal Problems and Influences]. Gestão e Desenvolvimento, 9(2000), 81-102.

Dozier, J.B., Husted, B.W., \& McMahon, J.T. (1998). Need for Approval in Low-Context and High-Context Cultures: A Communications Approach to Cross-Cultural Ethics. Teaching Business Ethics, 2, 111-125.

Duarte, F. (2006). Exploring the interpersonal transaction of the Brazilian jeitinho in bureaucratic contexts. Organization, 13(4), 509-527.

Ellison, F. (1984). Alfonso Reyes e Ribeiro Couto: Uma correspondência cordial [Alfonso Reyes and Ribeiro Couto: A cordial correspondence]. In J. A. Haddad, Miscelâneo de Estudos Literários: Homenagem à Afranio Coutinho [Miscellany of Literary Studies: Homage to Afranio Coutinho] (pp. 133-140). Brazil: Pallas.

Eubanks, R. L., McFarland, M. R., Mixer, S. J., Munoz, C., Pacquiao, D. F., \& Wenger, A. F. Z. (2010). Cross-Cultural Communication. Journal of Transcultural Nursing, 21(4), 137-150.

Fang, T. (2003). A critique of Hofstede's fifth national culture dimension. International Journal of Cross Cultural Management, 3, 347-368.

Fausto, B. (2001). A concise history of Brazil. (A. Brakel, Trans.) New York: Cambridge University Press.

Federman, M. (2004). McLuhan Thinking: Integral Awareness in the Connected Society. In Keynote Presentation for the McLuhan Program in Culture and Technology, University of Toronto. Toronto, Canada. 
Freyre, G. (1933). Casa-grande \& senzala: Formação da família brasileira sob o regime de economia patriarcal [The Masters and the slaves: A study in the development of Brazilian civilization. Rio de Janeiro, Brazil: Maia \& Schimidt.

Gladwell, M. (2008). Outliers: The story of success. New York: Back Bay Books.

Glenn, D. (2009). Jeitinho-Succeeding in Brazil. Industrial Heating, 76(1), 118.

Gobo, G. (2004). Sampling, representativeness and generalizability. In Seale, C., Gobo G., Gubrium, J., \& Silverman, D., Qualitative research practice (pp. 435-456). Thousand Oaks, CA: Sage.

Gomes, L. (2007). 1808: Como uma rainha louca, um principe medroso e uma corte corrupta enganaram Napoleao e mudaram a historia de Portugal e do Brasil [1808: How a crazy queen, a cowardly prince and a corrupt court tricked Napoleon and changed the history of Portugal and Brazil]. São Paulo, Brazil: Editora Planeta do Brasil.

Gomide, P. I. C. \& Pinsky, I. (2004). A influência da mídia e o uso das drogas na adolescência [The influence of media and the use of drugs during adolescence]. In Pinsky, I. \& Bessa, M.A. (Org.) Adolescência e drogas [Adolescence and drugs]. São Paulo, Brazil: Editora Contexto.

Gudykunst, W. B., Ting-Toomey, S., \& Chua, E. (1988). Culture and interpersonal communication. Newbury Park, CA: Sage.

Hall, E. T. (1976). Beyond culture. New York: Random House.

Hallenback, J. (2006). High context illness and dying in a low context medical world. American Journal of Hospice and Palliative Medicine, 23(2), 113-118. 
Hamburger, E. (2005). O Brasil antenado: A sociedade da novela [Brazil tuned: The society of the soap opera]. São Paulo, Brazil: Jorge Zahar Editora Ltda.

Hartog, S. (Director). (1993). Beyond Citizen Kane [Motion picture]. United States \& Brazil: Channel 4.

Helmreich, R.L., \& Merritt, A. (2000). Culture in the Cockpit: Do Hofstede's Dimensions Replicate? Journal of Cross-Cultural Psychology, 31(3), 283-301.

Hofstede, G. (1980). Culture's Consequences: International differences in work-related values. Beverly Hills, CA: Sage.

Hofstede, G. (1983). Cross-Cultural Research. Journal of Cross Cultural Research, 18, 285-305.

Hofstede, G. (1991). Cultures and Organizations: Software of the mind. London: McGraw-Hill.

Hofstede, G. (Ed.). (2001). Culture's consequences: Comparing values, behaviors, institutions and organizations across nations. Thousand Oaks, CA: Sage Publications.

Hofstede, G., Neuijen, B., Ohavy, D.D., \& Sanders, G. (1990). Measuring Organizational Cultures: A qualitative and quantitative study across twenty cases. Administrative Science Quarterly, 35, 286-316.

Holanda, S. B. (1995). Raízes do Brazil [Roots of Brazil]. Brazil: Companhia das Letras. IBGE: Instituto Brasileiro de Geografia e Estatística (2010). Censo demográfico 2010: Migração e deslocamento- resultado da amostra [Demographic census 2010: Migration and shift- sample result]. Retrieved October 22, 2012, from 
http://www.ibge.gov.br/home/presidencia/noticias/noticia_visualiza.php?id_notici $\underline{\mathrm{a}=1766}$

Jansen, G., \& Peshkin, A. (1992). Subjectivity in qualitative research. In M. D. LeCompte, W. L. Millroy, \& J. Preissle (Eds.), The handbook of qualitative research in education, (pp. 681-726). San Diego, CA: Academic Press.

Kellemen, P. (1995). Find a way around. In Summ, H. (Ed.), Brazilian Mosaic: Portraits of a diverse people and culture (pp. 129-132). Lanham, MD: Rowman \& Littlefield.

Kittler, M.G., Rygl, D., \& Mackinnon, A. (2011). Beyond Culture or Beyond Control? Reviewing the use of Hall's high-/low-context concept. International Journal of Cross Cultural Management, 11(1), 63-82.

Kowner,R., \& Wiseman, R. (2003). Culture and Status-Related Behavior: Japanese and American Perceptions of Interaction in Asymmetric Dyads. Cross-Cultural Research, 37, 178-210.

Leeds-Hurwitz, W. (1990). Notes in the history of intercultural communication: The Foreign Service Institute and the mandate for intercultural training. Quarterly Journal of Speech, 76, 262-281.

Lowe, S. (2001). In the Kingdom of the Blind, the One-eyed Man is King. International Journal of Cross-Cultural Management, 1(3), 313-332.

Lowenstein, A. (2002). Solidarity and conflicts in co-residency of three-generational immigrant families from the former Soviet Union. Journal of Aging Studies, 16, 221-241. 
Machado, L. Z. (2001). Family and Individualism: Contemporary Tendencies in Brazil. Interface - Comunicação, Saúde, Educação, 4(8), 11-26.

Malta, C. (2012, September 26). Empresas Americanas são as mais influentes [American companies are the most influential]. Valor Econômico. Retrieved November 30, 2012, from http://clippingmp.planejamento.gov.br/cadastros/noticias/2012/9/26/empresasamericanas-sao-as-mais-influentes

Maxwell, J. (1996). Qualitative research design: An interactive approach. Thousand Oaks, CA: Sage.

McCrae, R. R. (2000). Trait Psychology and the Revival of Personality and Culture Studies. American Behavioral Scientist, 44, 10-31.

McCrae, R. R., \& Terraciano, A. (2005). Personality profiles of cultures: Aggregate personality traits. Journal of Personality and Social Psychology, 89(3), 407-425.

McSweeney, B. (2002). Hofstede's Model of National Cutlural Differences and their Consequences: A Triumph of Faith_A Failure of Analysis. Human Relations, 55(1), 89-118.

McSweeney, B. (2002). The Essentials of Scholarship: A Reply to Geert Hofstede. Human Relations, 55(11), 1363-1372.

Mischel, W. (1990). Personality dispositions revisited and revised. In L. Pervin (Ed.), Handbook of Personality: Theory and Research (pp. 21-65). New York: Guilford Press. 
Moog, C. V. (1995). José Dias: Cultural Symbol. In Summ, H. (Ed.), Brazilian Mosaic: Portraits of a diverse people and culture (pp. 129-132). Lanham, MD: Rowman \& Littlefield.

Morse, R. M. (1995). Myth and evidence: Freyre and Sérgio Buarque. Luso-Brazilian Review, 47-57.

Mouralis, L. (1995). Liveliness of Spirit. In Summ, H. (Ed.), Brazilian Mosaic: Portraits of a diverse people and culture (pp. 102-106). Lanham, MD: Rowman \& Littlefield.

Oishi, S. (2004). Personality in Culture: A Neo-Allportian View. Journal of Research in Personality, 68-74.

Pekerti, A.A., \& Thomas, D.C. (2003). Communication in intercultural interaction: An empirical investigation of idiocentric and sociocentric communication styles. Journal of Cross-Cultural Psychology, 34(2), 139-154.

Peres, M. F. T. (2004). Firearm-related violence in Brazil. Centre for the Study of Violence, University of São Paulo. Retrieved October 22, 2012, from http://english.nevusp.org/index.php?option=com content\&task=view\&id=79\&Ite $\underline{\operatorname{mid}=37}$

Poasa, K.H., Mallinckrodt, B., \& Suzuki, L.A. (2000). Causal Attributions for Problematic Family Interactions: A Qualitative, Cultural Comparison of Western Samoa, American Samoa, and the United States. The Counseling Psychologist, 28(1), 32-60. 
Prado, C. J. (1967). The colonial background of modern Brazil. (S. Macedo, Trans.). Berkeley: University of California Press.

Prado, P. (1981). Retrato do Brasil: Ensaio sobre a tristeza brasileira [Portrait of Brazil: An essay about Brazilian sadness]. São Paulo, Brazil: Ibrasa.

Preston, C. E., \& Harris, S. (1965). Psychology of drivers in traffic accidents. Journal of Applied Psychology, 49(4), 284-288.

Puff, J. (2012, August 8). 'Jeitinho brasileiro me ajudou', diz executivo de missão da Nasa ['Brazilian jeitinho helped me,' says NASA mission executive]. BBC Brasil. Retrieved October 28, 2012, from http://www.bbc.co.uk/portuguese/noticias/2012/08/120808_nasa_brasileiro_ramo $\mathrm{n}$ _jp.shtml

Ramos, R. (1987). Grã-finos na Globo: Cultura e merchandising nas novelas [The elite on Globo: Culture and merchandizing in soap operas]. Petrópolis, Brazil: Vozes.

Rede Sarah de Hospitais de Reabilitação. (2012). Mapa da Morbidade por Causas Externas [Map of Morbidity by External Causes]. Associação das Pioneiras Sociais - Pesquisas. Retrieved October 22, 2012, from www.sarah.br

Rezende, C. B. (2008). Stereotypes and national identity: Experiencing the "emotional Brazilian"." Identities: Global Studies in Culture and Power, 103-122.

Ribeiro, D. (2000). The Brazilian people: The formation and meaning of Brazil. (G. Rabassa, Trans.) Gainesville: University Press of Florida. 
Ricardo, C. (1959). O homem cordial e outros pequenos estudos brasileiros [The cordial man and other small Brazilian studies]. Rio de Janeiro, Brazil: Instituto Nacional do Livro.

Ritzer, G. (1998). The McDonaldization thesis. Thousand Oaks, CA: Sage.

Roberts, K., \& Boyacigiller, N. (1984). Cross-National Organizational Research: The Grasp of the Blind Man. In B. M. Staw, \& L. L. Cummings (Eds.), Research in Organizational Behavior (pp. 423-475). Stamford, CT: JAI Press.

Robertson, R., \& White, K. E. (2007). What is Globalization? In Ritzer, G. (Ed.), The Blackwell Companion to Globalization (pp. 54-66). Malden, MA: Blackwell Publishing.

Rocha, J. C. (2003). As origens e os equívocos da cordialidade brasileira [The origins and misunderstandings of the Brazilian cordiality]. In J. Rocha, Nenhum Brasil Existe: Pequena Enciclopédia [No Brazil Exists: Small Encyclopaedia]. Rio de Janeiro: Topbooks.

Rocha, J. C. (2004). O Exílio do homem cordial [The Exile of the cordial man]. Brazil: Museu da República.

Rodrigues, G. M. A. (1994). O que são relações internacionais [What are international relations]. São Paulo: Editora Brasiliense.

Rogers, E.M., Hart, W.B., \& Miike, Y. (2002). Edward T. Hall and the history of intercultural communication: The United States and Japan. Keio Communication Review, 24, 3-26. 
Rosenn, K. (1995). Circumventing Legal but Unrealistic Obligations. In Summ, H. (Ed.), Brazilian Mosaic: Portraits of a diverse people and culture. Lanham, MD: Rowman \& Littlefield.

Rummel, R. J. (1966). Dimensions of conflict between nations, 1946-1959. Journal of Conflict Resolution, 10(1), 65-73.

Santos, J. F. (1995). Bypassing the system. In Summ, H. (Ed.), Brazilian Mosaic: Portraits of a diverse people and culture (pp. 142-148). Lanham, MD: Rowman \& Littlefield.

Schwartz, S. H. (1992). Universals in the Content and Structure of Values: Theory and Empirical Tests in 20 Countries. In M. Zanna (Ed.), Advances in Experimental Social Psychology (pp. 1-65). New York: Academic Press.

Schurz, W. L. (1995). Subjective, Unpredictable, and Capricious. In Summ, H. (Ed.), Brazilian Mosaic: Portraits of a diverse people and culture (pp. 120-126). Lanham, MD: Rowman \& Littlefield.

Sedikides, C., \& Gregg, A.P. (2008). Self-Enhancement: Food For Thought. Perspectives on Psychological Science, 3(2), 102-116.

Silva, C. E. L. (2002). Política e Comércio Exterior. In Lamounier, B. \& Figueiredo R. (Ed.), A Era FHC: Um Balanço [The FHC Era: A balance] (pp. 656) São Paulo: Cultura Editores Associados.

Singer, M. R. (2000). The Role of Culture and Perception in Communication. In G. Weaver (Ed.), Culture, Communication and Conflict -- Readings in intercultural relations. Boston, MA: Pearson Publishing. 
Strauss, A. C., \& Corbin, J. (1990). Basics of qualitative research: Grounded theory procedures and techniques. Newbury Park, CA: Sage.

Summ, H. (Ed.). (1995). Brazilian mosaic: Portraits of a diverse people and culture. Lanham, MD: Rowman \& Littlefield.

Suzuki, L.K., Davis, H.M., \& Greenfield, P.M. (2008). Self-Enhancement and SelfEffacement in Reaction to Praise and Criticism: The Case of Multiethnic Youth. ETHOS, 36(1), 78-97.

Tayeb, M. H. (1988). Organizations and National Culture: A Comparative Analysis. London: Sage.

Tayeb, M. H. (1994). Organizations and National Culture: Methodology Considered. Organization Studies, 429-446.

Tayeb, M. H. (2000). Hofstede. In M. Warner (Ed.), International Encyclopaedia of Business and Management (pp. 2574-2579). London: International Thomson Business Press.

Tayeb, M. H. (2001). Conducting Research Across Cultures: Overcoming Drawbacks and Obstacles. International Journal of Cross Cultural Management, 1(1), 91-108.

Ting-Toomey, S. (1999). Communicating across cultures. New York: Guilford Publications.

Ting-Toomey, S., \& Chung, L. (2005). Understanding intercultural communication. Los Angeles, CA: Roxbury Publishing.

Tomlinson, J. (2007). Cultural Globalization. In Ritzer, G. (Ed.), The Blackwell Companion to Globalization (pp. 353-366). Malden, MA: Blackwell Publishing. 
Torres, M. B., \& Rao, N. (2007). Disclosure and Truth in Physician-Patient Communicaiton: An Exploratory Analysis in Argentina, Brazil, India and the United States. Journal of Creative Communications, 2(3), 279-305.

Triandis, H. C. (1972). The analysis of subjective culture. New York: John Wiley. Usunier, C., \& Roulin, N. (2010). The Influence of High- and Low-Context Communication Styles on the Design, Content, and Language of Business-toBusiness Web Sites. Journal of Business Communication, 47(2), 189-227.

Vainfas, R. (1999). Colonização, miscigenação e questão Racial: Notas sobre equívocos e tabus da historiografia brasileira [Colonization, miscegenation and racial matters: Notes about errors and taboos of Brazilian historiography]. Tempo, 8, 1-12.

Van Der Vliert, E., Schwartz, S. H., Huismans, S. E., Hofstede, G., \& Daan, S. (1999). Temperature, Cultural Masculinity, and Domestic Political Violence: A CrossNational Study. Journal of Cross-Cultural Psychology, 30(3), 291-314.

Vygotsky, L. S. (1978). Mind in Society (M. Cole, Trans.). Cambridge, MA: Harvard University Press.

Vygotsky, L. S. (1986). Thought and Language (E. Hanfmann, \& G. Vakar, Trans.). Cambridge: MA: MIT Press.

Wagner, F., \& Ward, J. O. (1980). Urbanization and migration in Brazil. American Journal of Economics and Sociology, 39(3), 249-259.

Weaver, G. (2000). Contrasting and Comparing Cultures. In G. Weaver (Ed.), Culture, Communication and Conflict -- Readings in intercultural relations. Boston, MA: Pearson Publishing. 
Wilcken, P. (2004). Empire Adrift: The Portuguese Court in Rio de Janeiro, 1808-1821. London: Bloombury.

Wimot, W., \& Hocker, J. (2007). Interpersonal conflict. New York: McGraw-Hill.

Yeh, R. S., \& Laurence, J. J. (1995). Individualism and Confucian Dynamism: A Note on Hofstede's Cultural Root to Economic Growth. Journal of International Business Studies, 26(3), 655-669. 


\section{Appendix A: Initial e-mail sent to all my Brazilian contacts in my e-mail contact list}

Dear Friends:

Please, print or forward this e-mail below to friends, family, co-workers, acquaintances at you church, university, clubs, etc.

Thank you,

Thais

Greetings,

You are receiving this e-mail because our mutual acquaintance thought you might be interested in participating in my study. My name is Thais and I am a Master's Degree Candidate in the Conflict Resolution program at Portland State University, in Portland, Oregon, U.S.

I am studying the influences that urbanization and American-influenced cultural globalization have on intrafamilial conflict in distinct generations in Brazil. In order to advance this study, I would like to interview 6 dyads of fathers and sons. Ideally, fathers must have been born in small/rural towns and children, who should be 18 or older, must have been born in large/urbanized towns.

I will come to the participants' home, or any place they deem to be more comfortable, and will perform individual interviews for one hour to two hours each. The questions will not be specific to the participants' personal experiences pertaining to their intrafamilal conflict. Instead, they will be pertaining to general intrafamilial conflict, disciplinary methods used by parents to correct unwanted behavior, and participant's reactions towards conflictive situations within the 
family. Each participant has the right to refuse to answer any of the questions asked or to withdraw their participation from the study without having to give any explanations to the researcher and without any consequences.

I would like to explore whether the transformations that usually occur in younger generations due to globalized cultural influences (such as exacerbated individualism, need of personal space, and shifts in societal norms) are generating conflict between parents and their children.

Any information that is obtained in connection with this study and that can be linked to you or identifies you will be kept confidential. All comments which would identify you to your son/father will be obscured or omitted. Your participation in this study will also be kept confidential to everyone, including our mutual acquaintance. If there is something of particular significance which might identify you, I will come back to you and specifically ask permission.

Although, you will not receive any material compensation to participate in this study, I hope that you will benefit by engaging in a self-reflective thought process while telling your story, and will have a new perspective regarding your intrafamilial conflict during the process, and once you learn about the findings. Another benefit is that your disclosures and reflections will immensely contribute to the fields of conflict resolution and counseling where the focus is on intergenerational conflict. There are no studies in Brazil that address this particular issue and your participation will be greatly valued. 
If you are interested in participating in this study, please write me an email and I will give you more detailed information about the research. I will be arriving in Brazil in November/2011 for the interviews and would like to schedule them as soon as possible at convenient times for you and your family. I would also like to ask you to talk about this study with people you know, since word of mouth is an effective tool to publicize a study and recruit participants. My e-mail is: thaislarosa@hotmail.com 


\section{Appendix B: Interview Questions}

1) Describe yourself:

i. As part of your family; and,

ii. As part of the Brazilian society.

2) (Parent) How many children do you have? What is the place of the child I am interviewing in the birth order? (Adult Child) How many siblings do you have and what is the birth order?

3) (Parent) Did you see any differences in the way you raised your first and last child? (Child) Did you see any differences between the way you were raised and your older or younger sibling was raised?

4) What are the differences between the ways parents educated their kids in the past and now?

5) What were the major influences on you regarding the upbringing of your children?

6) When you need to make a difficult personal decision, what do you consider and whom do you consult?

7) Talk about your relationship with your son/father. In which ways are you similar and different?

8) What are the best ways to discipline a child?

9) (Parent) If your son/daughter was doing anything that you disapprove of, what would be your major concerns? (Adult Child) When your father has expressed disapproval of your actions, what were his major concerns? 
10) (Parent) When you needed to prevent your son/daughter from doing something, as a child and as an adult, what methods did you use? (Adult Child) When you father/mother was trying to prevent you from doing something, as a child and as an adult, what methods did he/she use?

11) (Parent) If your son/daughter was doing heavy drugs, what would be the first 3 things you would tell him? (Adult Child) If you were doing heavy drugs, what are the first three things you father would tell you?

12) Talk about a conflict you have or have had with your son/father. Has it been resolved? How?

13) Think of 3 ways communication could go bad with you son/father.

14) In what ways urbanization, technological advancements and globalization have hurt or improved the way people deal with conflict? 